Cómo citar este trabajo: Delgado Viñas, C. (2018). Los procesos de metropolitanización dispersa: Castro Urdiales (Cantabria) en la región urbana de Bilbao. Boletín de la Asociación de Geógrafos Españoles, 78, 474-517. doi: http://dx.doi.org/10.21138/bage.2721

\title{
Los procesos de metropolitanización dispersa: Castro Urdiales (Cantabria) en la región urbana de Bilbao
}

\author{
Dispersed metropolitanisation processes: \\ Castro Urdiales (Cantabria) in the Bilbao urban region
}

\section{Carmen Delgado Viñas}

carmen.delgado@unican.es

Departamento de Geografía, Urbanismo y Ordenación del Territorio

Universidad de Cantabria (España)

\section{Resumen}

Castro Urdiales (Cantabria) es un ejemplo paradigmático de la problemática de los actuales procesos de urbanización, del crecimiento de los pequeños núcleos periféricos de una aglomeración urbana a partir de la descentralización y dispersión intrametropolitana, del cambio morfológico de los espacios urbanos a consecuencia del "estallido" de la ciudad y la diseminación de fragmentos construidos de la misma por las áreas rurales más o menos próximas. No obstante, también presenta algunas singularidades provenientes, sobre todo, de su pertenencia políiticoadministrativa a una Comunidad Autónoma distinta de aquélla en la que se encuentra el núcleo central y las demás entidades integrantes de la región urbana, el País Vasco. Los límites autonómicos no parecen haber sido un obstáculo para la configuración funcional del área metropolitana más allá de los confines que deslindan el territorio polííico-administrativo, pero sí producen "efectos de frontera" como consecuencia de las actuaciones de las administraciones implicadas, locales y autonómicas, en materia urbanística y de dotación de infraestructuras, servicios y equipamientos.

Palabras clave: metropolitanización; región urbana, periurbanización; Castro Urdiales; Cantabria. 


\begin{abstract}
Castro Urdiales (Cantabria) is a prime example of the problem with current urbanisation processes, the growth of small peripheral population centres, the urban agglomeration caused by intrametropolitan decentralisation and dispersion, and the morphological changes to urban areas as a result of the "explosion" of the city and the dispersal of its built fragments throughout nearby or more distant rural areas. However, it also has some specific features, above all those resulting from the fact that politically and administratively it belongs to a different Autonomous Community than the main population centre and other areas comprising the conurbation, which are part of the Basque Country. The boundaries between the autonomous communities do not seem to have been an obstacle to the functional configuration of the metropolitan area beyond the borders that define the political and administrative region, but they do produce "border effects" as a result of the actions of the local and regional bodies involved in town planning and the provision of infrastructures, services and equipment.
\end{abstract}

Key words: metropolitanization; urban region; periurbanization; Castro Urdiales; Cantabria.

\title{
1 Introducción
}

Desde el siglo XIX en España ha tenido lugar un proceso de urbanización similar al de otros países europeos, aunque con diferencias cronológicas y de ritmo. La aceleración de ese proceso se ha producido en la segunda mitad del siglo XX de forma general y también en el caso de las ciudades españolas, que han experimentado en este tiempo las mutaciones más significativas en sus estructuras y morfología a la vez que se modificaba el sistema urbano (Gil \& Bayona, 2012; Roca et al., 2012; Nel.lo, 2017) a través de una dinámica de metropolitanización definida por la consolidación y transformación de las áreas metropolitanas tradicionales (Rodríguez, 2009; Pons, 2012).

Los espacios urbanos del sur de Europa han empezado a experimentar notables movimientos de dispersión de la población desde los años ochenta, y sobre todo de los noventa, explicados en principio bajo las teorías de la "contraurbanización" florecientes en esos años (Berry, 1976; Arroyo, 2001). En la mayoría de los casos tales dinámicas consistieron básicamente en diferentes formas de descentralización intrametropolitana a partir de la redefinición de los mercados laboral y residencial (Arroyo, 2002; Feria, 2010) apoyada en la mejora de la accesibilidad y conectividad (Wiel, 1999). Factores a los que hay que añadir el diferencial de precios entre unas y otras zonas del área metropolitana, que estimula la movilidad residencial desde los núcleos centrales más grandes a los periféricos más pequeños; un aspecto que algunos autores destacan como factor principal del proceso y elemento clave para aproximarse al estudio del fenómeno urbanizador en el presente (Feria \& Andujar, 2015). 
De forma general la metropolitanización actual consiste en la creciente consolidación de áreas metropolitanas dispersas y policéntricas en las que la ciudad central pierde población al tiempo que la ganan los núcleos urbanos de las coronas periféricas (Dematteis, 1991; Nel.lo, 1998; Font, 2007). Se trata, pues, de un conjunto de cambios estructurales y morfológicos intrametropolitanos cuyo resultado es la sustitución del modelo metropolitano clásico (Vinuesa \& Vidal, 1991), hasta el punto de que empieza a quedar obsoleto el concepto mismo de área metropolitana (Ascher, 1995, 2009; Corboz, 1995; Capel, 2003). Las fuerzas que han producido esa metamorfosis provienen de lo que C. de Mattos (2010) considera una nueva fase de modernización capitalista que ha sido documentada en detalle para los países de capitalismo avanzado (Soja, 1997, 2000, 2008). En opinión de Gaja i Díaz (2004), que comparto, el crecimiento metropolitano disperso es uno de los fenómenos que, de una forma más clara, define la evolución de las ciudades españolas durante el último medio siglo.

En las regiones metropolitanas maduras la dinámica se orienta hacia la descentralización y el cambio funcional y territorial de los núcleos perimetropolitanos, dando lugar a un nuevo modelo caracterizado por la desarticulación territorial en el que los espacios plenamente urbanos y los rurales se intercalan con una gran variedad de usos y tipos de organización espacial (Feria, 1999, 2004, 2006; Vahí et al., 2015).

Hace unos años Ascher (1995) afirmaba que se ha abierto paso paulatinamente un nuevo estadio de urbanización que adopta como principio específico la desconcentración en múltiples facetas. El mismo autor, apoyándose en el concepto de revolución urbana, considera que desde finales del siglo XX se está produciendo la tercera revolución urbana a la que denomina "neourbanismo" (Ascher, 2004). Uno de los cinco cambios que caracterizan esta tercera revolución urbana moderna es, según dicho autor, la metapolización, entendida como un doble proceso de metropolización y de formación de nuevos tipos de territorios urbanos. Estos territorios o regiones metropolitanas ya no se reducen a la ciudad central y su entorno o área metropolitana, sino que ahora son espacios discontinuos en los que alternan zonas compactas con otras dispersas, nuevas centralidades y áreas marginales, espacios urbanizados y otros preservados o expectantes (Borja y Castells, 2005), a modo de una ciudad de ciudades con una dinámica de "metropolización expandida" (de Mattos, 2001) que, progresivamente, va superando sus límites, ocupando los espacios rurales que encuentran en su camino (Martínez, 2016). Las áreas metropolitanas se convierten así en espacios de diversidad y de contraste, espacios fragmentados, de conflicto y, en definitiva, espacios vulnerables (Ponce, 2007; Méndez, 2010; Méndez et al., 2015; Cuadrado, 2016). Son espacios urbanizados en los que la extensa periferia, "se caracteriza por su confusión formal y su desarticulación territorial, en la que los usos urbanos [...] se entremezclan con los rurales [...] en una amalgama de funciones y tipologías formales" (Feria, 1999). El resultado último es una forma de hábitat urbano nueva, distinta de la ciudad tradicional y de la metrópolis 
convencional, calificada de "posturbanidad" y caracterizada por "nuevas formas post-modernas y pautas de vida urbana que están en continuo desafió con los estilos bien establecidos de análisis urbanos" (Soja, 1997, p. 38).

Se trata del proceso que Indovina identificaba cronológicamente con el último cuarto del siglo XX y calificaba de "nueva metropolización del territorio" (Indovina, 2003, 2007). O bien, como sostenía no hace mucho tiempo Capel, "La urbs, el espacio construido con una densidad de edificación, resulta difícil de delimitar y de definir, por la extensión de la urbanización difusa, que la ha expandido ampliamente por todo el territorio de lo que, primero, se llamaban ciudades, luego se convirtieron a veces en áreas metropolitanas y ahora, cada vez más, se configuran como regiones metropolitanas, e incluso rebasan ampliamente ese marco territorial" en la era de la "Urbanización Generalizada" (Capel, 2010:6).

Aunque en apariencia pudiera parecer contradictorio, al compás del proceso de metropolitanización reciente se ha ido afianzando el protagonismo de las ciudades pequeñas y medias y, en consecuencia, se ha renovado su estudio desde la Geografía y disciplinas afines (Bell \& Jayne, 2006; Capel, 2009;), en particular a raíz de la publicación de la Estrategia Territorial Europea en 1999 y la revalorización de su funcionalidad como intermediarias potenciales entre las grandes ciudades y los espacios rurales y como equilibradoras territoriales frente a las macrocefalias metropolitanas ya que "Las ciudades de tamaño medio [...] han sido las grandes receptoras de la migración metropolitana" (Pujadas, 2009).

En coherencia con las nuevas situaciones, las áreas metropolitanas vienen siendo objeto de estudio frecuente por parte de la Geografía Urbana española en las últimas décadas y existen numerosas investigaciones que se están ocupando de distintos aspectos vinculados a esta forma urbana, algunas de ellas citadas antes. Son abundantes, asimismo, los estudios sobre las principales áreas metropolitanas en su conjunto y desde la perspectiva de la ciudad central.

Mucho menos voluminosa es la literatura académica dedicada a analizar las nuevas dinámicas desde la perspectiva de la evolución y problemática de los propios núcleos perimetropolitanos, que son los que están experimentando cambios especialmente notables en su transformación socioeconómica, configuración morfológica y estructural, conflictos, etc., a partir de las últimas décadas del siglo XX. Ese enfoque es el que se ha adoptado en la investigación en que se apoya el presente artículo, que toma como caso de estudio el de la ciudad cántabra de Castro Urdiales, integrada en la periferia de la región urbana de Bilbao.

Castro Urdiales, aunque a pequeña escala, es un modelo paradigmático del proceso español de urbanización en las distintas fases de su evolución (Delgado, 2011, 2015). Es, asimismo, un magnífico ejemplo de la problemática de las actuales dinámicas de urbanización, del crecimiento de los pequeños núcleos periféricos de una aglomeración urbana a partir de la descentralización y 
dispersión intrametropolitana y del cambio morfológico de los espacios urbanos a consecuencia del "estallido" de la ciudad y la diseminación de fragmentos construidos de la misma por las áreas rurales más o menos próximas.

No obstante, presenta también algunas singularidades que requieren ser consideradas, sobre todo las provenientes de la pertenencia político-administrativa del municipio castreño a una Comunidad Autónoma, Cantabria, distinta de aquélla en la que se encuentra el núcleo central y las demás entidades integrantes de la región metropolitana, el País Vasco. Los límites autonómicos no parecen haber sido un obstáculo para la configuración funcional del área metropolitana más allá de los confines que deslindan el territorio político-administrativo, pero sí producen "efectos de frontera" como consecuencia de las distintas actuaciones de las administraciones implicadas, locales y autonómicas, en materia urbanística y de dotación de infraestructuras, servicios y equipamientos. Salvando las distancias, como en el caso del área metropolitana luxemburguesa (Berger, 2005), a la polarización centro/periferia clásica de toda área metropolitana se añaden aquí las características diferenciales "transfronterizas" relacionadas sobre todo con las oportunidades de empleo, los salarios, los precios del mercado inmobiliario, las condiciones de vida, el acceso a los servicios e, incluso, las disparidades fiscales.

En el mismo sentido cabe destacar que la articulación territorial de Castro Urdiales con el área bilbaína no es un hecho completamente nuevo sino que se remonta a mucho tiempo atrás, por lo que puede ser entendida como un antecedente precoz del proceso de metropolitanización dispersa que ha dado origen al modelo urbano contemporáneo.

Al margen de este hecho, hoy es incuestionable que el término municipal de Castro Urdiales está integrado funcionalmente en el área metropolitana bilbaína, a pesar de lo cual no suele incluirse en esta territorialidad, ni estadística ni académicamente, tal vez como consecuencia de la aceptación, muchas veces incuestionada, del carácter categórico de los límites político-administrativos. ${ }^{1}$

El municipio de Castro Urdiales, uno de los más extensos de Cantabria $\left(96,7 \mathrm{~km}^{2}\right)$, está situado en el extremo oriental de su litoral, en el límite entre esta Comunidad Autónoma y la del País Vasco (Figura 1). Esa posición geográfica es una de las principales señas de identidad de este espacio, a la vez que la clave para entender la dinámica territorial pasada y presente y, en particular, la evolución reciente.

Durante varios siglos los vínculos de la villa de Castro Urdiales con el territorio vizcaíno fueron muy intensos ya que formó parte del Señorío de Vizcaya hasta 1471. Tras varios intentos fallidos, en 1738 Castro Urdiales y su jurisdicción, obtuvieron el permiso real para incorporarse otra vez al

1 Salvo error u omisión, uno de los pocos estudios que incluyen a Castro Urdiales en el área metropolitana bilbaína es el de Marmolejo, Ruiz y Tornés (2015). 
Señorío, aunque fue por un período de tiempo muy breve. Desde 1833 el término municipal pasó a formar parte de la Provincia de Santander, precursora de la actual Comunidad Autónoma de Cantabria. No obstante, la articulación funcional de ambos territorios no quedó interrumpida, sino todo lo contrario.

Figura 1. El término municipal de Castro Urdiales (Cantabria) y su situación en el contexto territorial del área metropolitana vizcaína

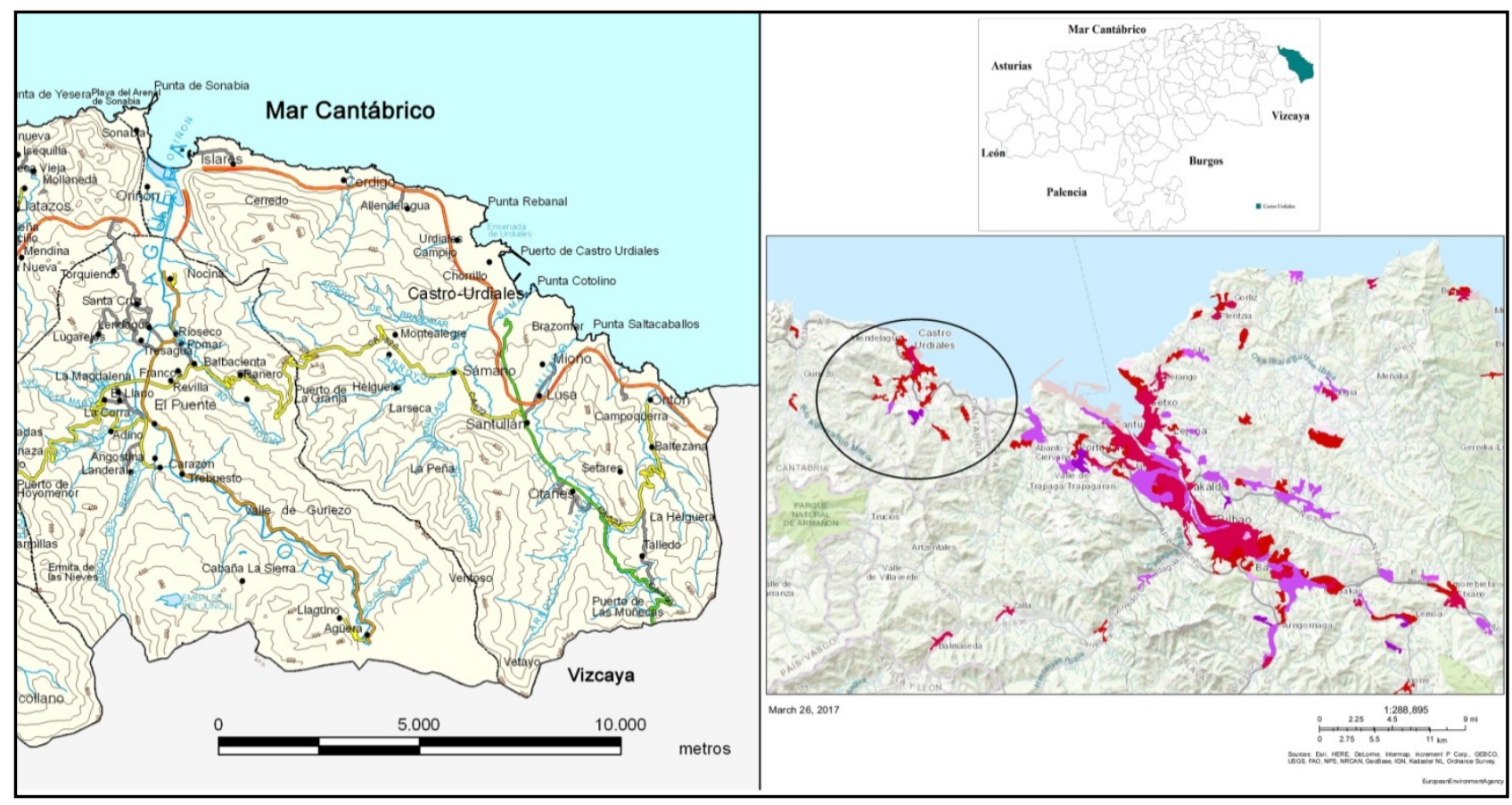

Fuente: elaboración propia a partir de mapas del IGN (2011)

y del Proyecto Corine Land Cover (2017)

En este territorio están empadronados 31901 habitantes en 2016, si bien otros indicadores indirectos permiten elevar la cuantía a más del doble; de ser así, habría que considerar a Castro Urdiales como el segundo municipio más poblado de Cantabria tras la capital regional, Santander. El creciente volumen de población y la elevada densidad de la misma $\left(329,9\right.$ hab $\left./ \mathrm{km}^{2}\right)$ son situaciones nuevas motivadas por la integración del municipio en la aglomeración urbana bilbaína, como pone de manifiesto el hecho de que la mayoría de los 16734 habitantes que ha ganado desde 1996 proceda del País Vasco, en especial de la provincia de Vizcaya.

La población castreña se distribuye de forma irregular entre 14 entidades de población. En 2016 en la capital municipal, la ciudad homónima de Castro Urdiales, residen 25202 personas (79 \% de la población municipal), en tanto que los otros trece núcleos de población, barrios o pedanías (Allendelagua, Baltezana, Cérdigo, Islares, Lusa, Mioño, Ontón, Oriñón, Otañes, Sámano, Santullán, Sonabia y Talledo) tienen unas dimensiones demográficas minúsculas, con la excepción de Sámano, que tiene 2905 habitantes. Es muy significativo también que el volumen de población 
de cada uno de estos núcleos y, sobre todo, su evolución reciente estén directamente relacionadas con su proximidad al límite de Vizcaya y con la conectividad con la provincia vasca y, en particular, con Bilbao de la que dista apenas 35 kilómetros.

La movilidad residencial reciente se ha visto favorecida por la mejora de la accesibilidad impulsada por la apertura de la autovía A-8 en 1991. La tendencia ha coincidido con el ciclo constructor acertadamente calificado por Burriel (2008) como la "década prodigiosa" del urbanismo español, que ha tenido en Castro Urdiales un excelente prototipo. Ambos procesos han quedado suspendidos temporalmente por los efectos de la crisis socioeconómica y, en particular, por el estallido de la "burbuja inmobiliaria" que ha puesto un freno coyuntural a las dinámicas de metropolitanización (Burriel, 2014; Nel.lo, 2017).

\section{Los primeros pasos hacia la integración funcional de Castro Urdiales en el área urbana de Bilbao}

Desde su refundación medieval Castro Urdiales fue, ante todo, una villa marinera especializada en la actividad pesquera, que alcanzó un gran auge durante los siglos XVI y XVII. ${ }^{2}$ También durante ese tiempo tuvo un fuerte impulso el transporte de cabotaje, pese a la intensa competencia de Bilbao y la consolidación de la villa vasca como principal puerto de Castilla.

La moderna industria conservera cántabra se gestó en Castro Urdiales a finales de la primera mitad del siglo XIX, probablemente muy vinculada al desarrollo coetáneo del mismo sector en algunas villas del litoral vasco (Escudero, 2000). La primacía ostentada al principio por Castro Urdiales fue perdiendo peso desde finales del siglo XIX a favor de otras villas próximas (Santoña y Laredo), a la vez que llegaba a su apogeo la extracción y exportación de mineral de hierro, punto de partida del proceso de expansión y transformación del espacio urbano de la villa, elevada a la categoría de ciudad en 1905.

El apogeo de la minería del hierro entre 1880 y 1930 significó la consolidación de un fuerte núcleo de empresarios vizcaínos y castreños que operaban en los yacimientos de Somorrostro, entre la villa cántabra y la bilbaína, lo que implicó la intensificación de los vínculos anudados secularmente. Desde entonces, la dinámica demográfica y urbanística de la ciudad ha estado cada vez más ligada a las relaciones con el área urbana bilbaína.

La población de Castro Urdiales experimentó en el último cuarto del siglo XIX un importante aumento como consecuencia del crecimiento económico asociado a la industria conservera, primero, y, sobre todo, a la explotación minera a partir de las últimas décadas de la centuria. La

2 Sobre la evolución demográfica y socioeconómica de Castro Urdiales, desde sus orígenes hasta el último cuarto del siglo XX, pueden consultarse los trabajos de C. Delgado Viñas (2011 y 2015). 
población municipal se duplicó en la primera mitad del siglo al pasar de 2.085 habitantes en 1822 a 4555 en 1860. Desde ese momento el ritmo del incremento poblacional fue extraordinario: de la cantidad anterior se pasó a 7623 habitantes en 1877, 9466 en 1887 y 14191 en 1900 (Figura 2).

El declive de la actividad minera guarda estrecha relación con el retroceso poblacional que tuvo lugar a partir de la segunda década del siglo XX, que abre una larga fase de decrecimiento y estancamiento demográfico de modo que población municipal no superó la cifra de 12000 habitantes hasta 1970, año en cuyo censo aún figuraba un número de vecinos levemente menor del que constaban en 1910 y 1930; habría que esperar a 1992 para recuperar el volumen de población censada en 1900. En consecuencia, el notable aumento del parque de viviendas y la ampliación del espacio urbano que tuvieron lugar durante ese tiempo, como se expondrá más adelante, no guardan relación alguna con la demanda de vivienda principal de la población castreña, sino con la de vivienda secundaria y vacacional para población procedente de otros lugares, en particular de la emergente área metropolitana de Bilbao (Feria, 2013).

Figura 2. Evolución de la población de Castro Urdiales durante los siglos XIX y XX

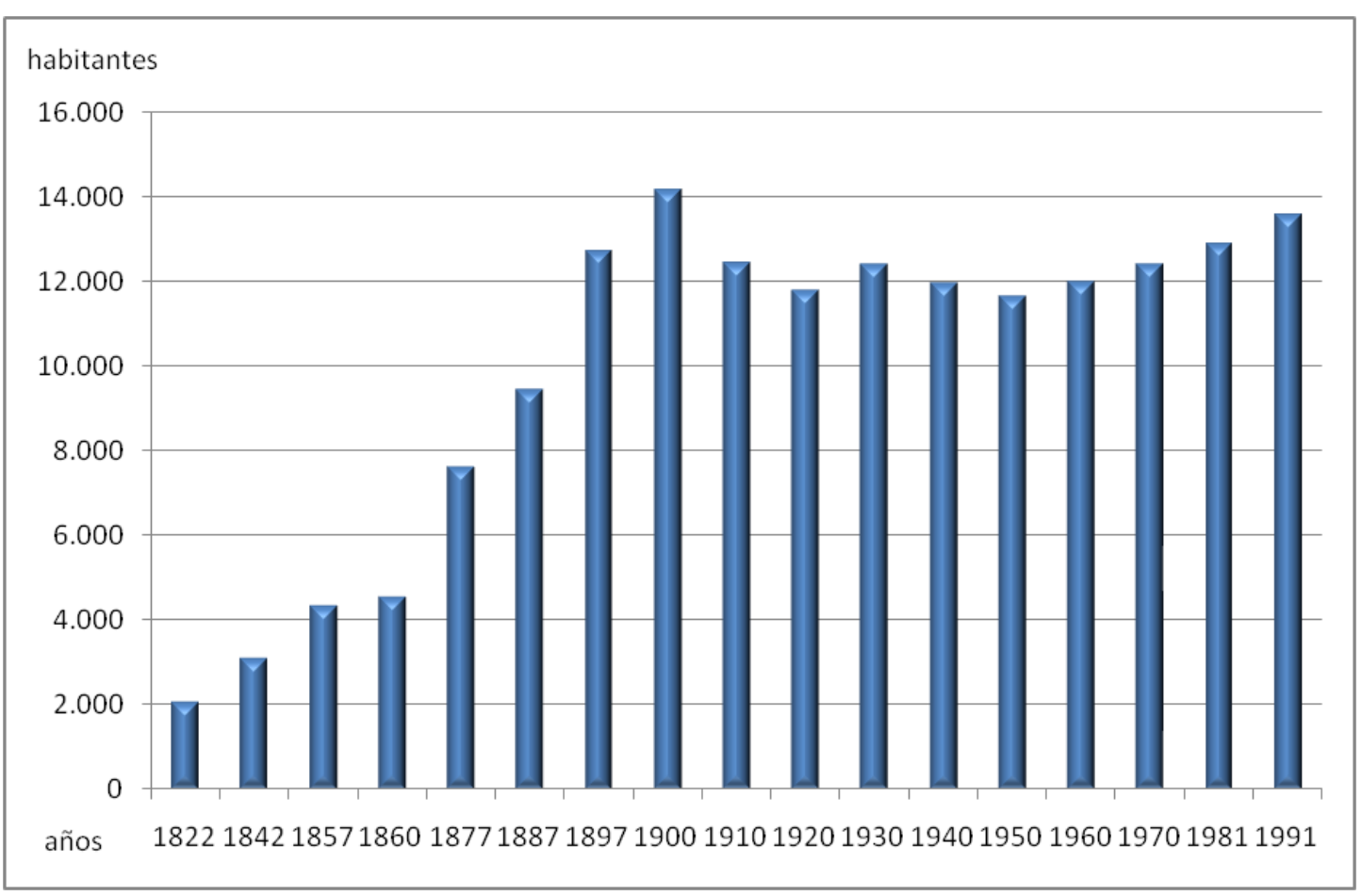

Fuente: elaboración propia a partir de los Censos de Población y Vivienda (INE, 1822-1991)

Desde un punto de vista urbanístico, el espacio de la villa había cambiado muy poco desde su refundación medieval (Delgado, 2015). El minúsculo casco histórico se adaptaba perfectamente a la línea de base marcada por la ensenada y el puerto, que definieron la forma semicircular del plano, y se estructuraba a partir de tres conjuntos rodeados por la muralla que se erigió a principios del siglo XIII: el espacio institucional, el castro, la puebla vieja o media villa de arriba y la 
puebla nueva o media villa de abajo, que se conservaron bien diferenciados hasta la segunda mitad del siglo XIX (Figura 3).

La muralla empezó a ser derruida en 1866, aunque su demolición no se completó hasta 1895, como consecuencia del imperativo impuesto por el trazado de dos líneas férreas, que cercaron de nuevo el núcleo urbano, y la construcción de la estación de la línea Castro-Traslaviña. Una vez derribado el lienzo meridional fueron surgiendo nuevos edificios y calles en los terrenos que bordeaban el flamante muelle de Ocharan. El nuevo espacio urbano, la primera ampliación que desbordaba el recinto cercado de origen medieval, adoptó la tipología de una ciudad jardín, con viviendas unifamiliares, villas y palacetes de veraneo para la burguesía, articulada en torno al Paseo de la Playa de Brazomar y el antiguo camino de Bilbao. Hasta mediados del siglo XX quedaron prácticamente detenidos los procesos de reforma y ampliación del espacio urbano ya que fueron muy pocas las actuaciones urbanísticas reseñables durante los años cuarenta y cincuenta. Cabe destacar, por sus efectos posteriores, que se produjo la fijación del área de ciudad jardín de Brazomar, donde siguieron construyéndose villas de veraneo e, incluso, algunas pequeñas urbanizaciones de chalets. Al mismo tiempo, el sector noroccidental de Los Huertos se consolidó como un barrio obrero donde el Instituto Social de la Marina edificó una barriada de pescadores y la Obra Sindical del Hogar construyó bloques de viviendas modestas.

Pero el impulso de la verdadera transformación urbanística de Castro Urdiales, desencadenada por su confirmación como núcleo turístico de veraneo para capas sociales cada vez más extensas, no se produjo hasta los años sesenta y setenta del siglo XX. Elocuentemente, el principal sector de crecimiento espacial se extendió hacia el sureste del núcleo, como ampliación de la ciudad jardín donde, junto a las villas y quintas tradicionales, comenzaron a levantarse bloques de viviendas permanentes $y$, en mayor medida aún, de apartamentos vacacionales, en muchas ocasiones en sustitución de las residencias veraniegas decimonónicas. ${ }^{3}$

Puede afirmarse sin duda alguna que el auge de la edificación residencial se inicia en Castro Urdiales en los años sesenta del siglo XX, cuando se encontraban en la ciudad unas 1000 viviendas en construcción. Frente a las 1584 viviendas levantadas en los veinte años que transcurren de 1941 a 1960 que figuran en el Censo de Viviendas de 2001, aparecen censadas 1272 viviendas edificadas en la década de los años sesenta, 2851 entre 1971 y 1980 y 2.386 de 1981 a 1990; lo que significa que las más de 6500 viviendas construidas en esos treinta años representan más de

3 En la década de los sesenta se construyó el primer gran hotel moderno, un edificio de cinco plantas que se levantó en los terrenos de la finca "Miramar" adquirida por la empresa vizcaína Construcciones lbarra para edificar, además, tres torres de once plantas y dos bloques de seis pisos con un total de 204 apartamentos. Esta actuación inauguró una larga etapa de conflictividad urbanística ya que el complejo Ibarra fue denunciado por irregularidades en 1968. 
un tercio $(34,6 \%)$ del parque inmobiliario que tenía Castro Urdiales a principios del siglo XXI (Figura 5).

\section{Figura 3. Vista aérea de Castro Urdiales a mediados del siglo XX. El castro en primer plano}

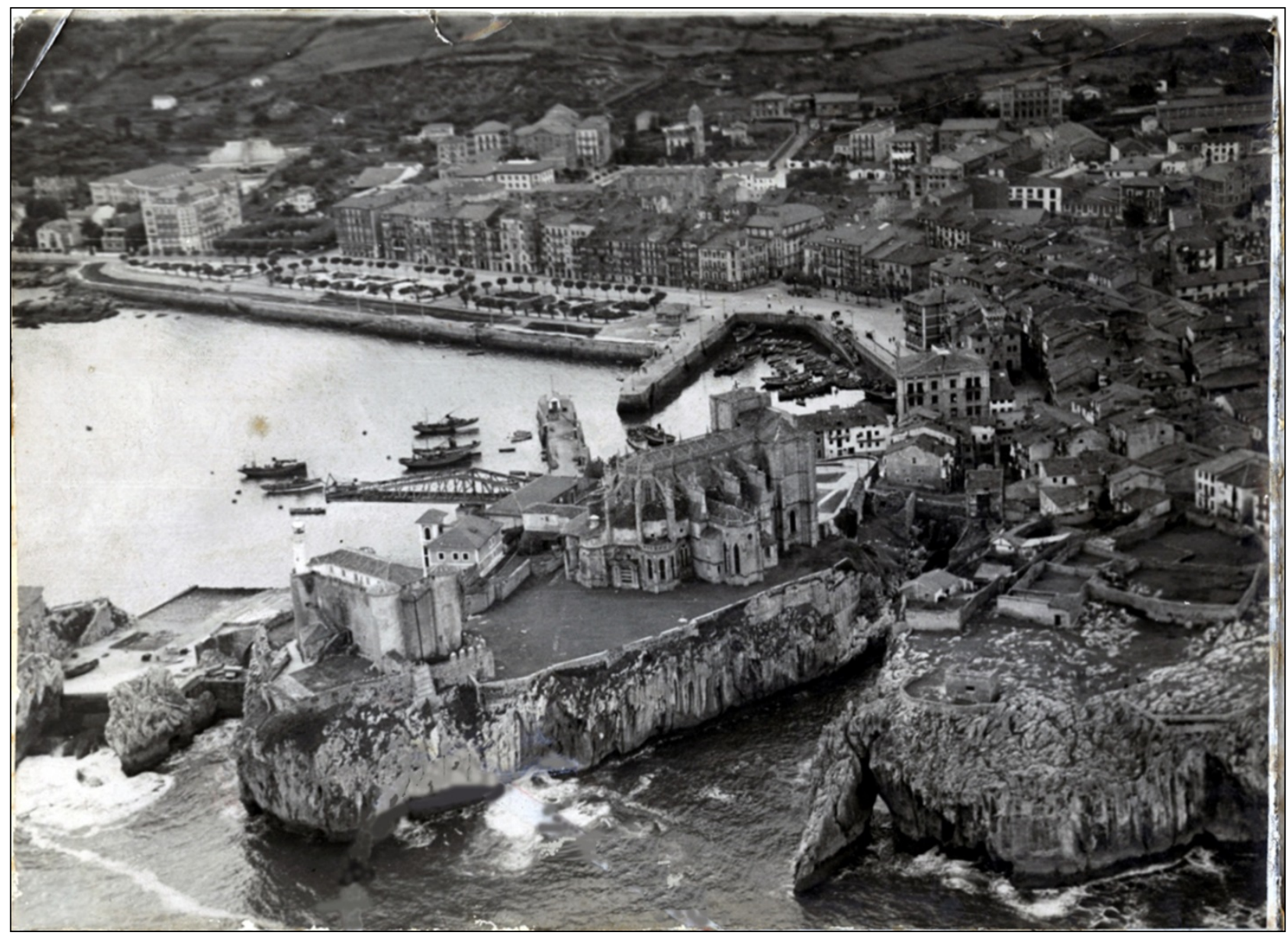

Fuente: Centro de Documentación de la Imagen de Santander (CDIS) (s.f.)

La mayor parte de esas nuevas viviendas tuvieron como uso prioritario el de segundas residencias o viviendas vacacionales. Tal conclusión viene avalada por los datos que proporciona el Censo de 1991: el 55,9\% de las 9115 viviendas inscritas en el municipio eran viviendas no principales (Tabla 1).

Esta primera fase de ímpetu constructor condicionó la elaboración y aplicación del primer Plan General de Ordenación Urbana (PGOU) de la ciudad, el aprobado el 23 de febrero de 1965, del que apenas queda constancia en las dependencias municipales. ${ }^{4}$ Realizado en la etapa culminante de la mentalidad "desarrollista", el Plan estuvo vigente algo más de treinta años, período de tiempo

4 En el Archivo Histórico Municipal de Castro Urdiales únicamente se conservan las Normas Urbanísticas fechadas en 25 de mayo de 1965; el plano reproducido en las normas urbanísticas se corresponde estrictamente con los planos de zonificación originales del Plan, según se explicita. En el mismo legajo, se encuentra otra documentación previa y posterior a la aprobación del Plan que, hasta donde es posible, suple la ausencia de los documentos principales, que tampoco están disponibles para consulta en otras dependencias municipales (Leg. 701, expediente 1). 
durante el cual se construyeron más de 10.500 viviendas, la mayor parte de las veces acogiéndose a numerosas e importantes modificaciones del Plan o, en otros ocasiones, simplemente ignorándolo.

Poco después se aprobó el Plan Parcial de Cotolino-Arcisero (1966) justificando la modificación porque "es preciso crear en Castro Urdiales, ciudad turística y veraniega por excelencia, una nueva zona que facilite solares y permita la construcción principalmente dedicada a la estancia estival" 5

Pese todo, parece que el Plan de 1965 se consideró demasiado restrictivo para las expectativas de construcción de viviendas vacacionales, de lo que se tenía un extraordinario modelo de referencia en la vecina ciudad de Laredo. En consecuencia, desde 1972 se extendió la idea de revisar con urgencia el Plan vigente para adecuarlo a las nuevas demandas con el argumento, poco verosímil en ese momento, del crecimiento de la población y de que "se ha demostrado que son insuficientes las zonas destinadas a la instalación de industrias". 6

Tres años más tarde se inició el proceso de redacción de un nuevo PGOU fundamentada, en esta ocasión, en el objetivo de adaptarse a la Ley de Régimen del Suelo y Ordenación Urbana de 2 de mayo de 1975. Pero las verdaderas razones se exponían de forma palmaria en la solicitud de una subvención para su elaboración. Entre ellas sobresalen dos: por un lado, la oportunidad de integración en el área metropolitana de Bilbao que ofrece a la ciudad el proyecto de construcción de "la autopista del Cantábrico Bilbao Castro Urdiales, lo que situará nuestra Ciudad de la zona urbana conocida con el nombre de Gran Bilbao a 15 minutos de distancia..."; por otro se hace referencia a la creciente demanda de residencias secundarias emanada de la proximidad del área metropolitana de la Ría de Bilbao. Finalmente se hacía mención a la futura construcción de un Polígono Industrial de 114 ha y, como de pasada, a que "Por la Empresa Castro Mar S.A. se va a promover recientemente la construcción de más de cuatro mil viviendas en los Polígonos denominados Cotolino, Arcisero, La Cruz y Dícido, cuyo planeamiento ha sido aprobado recientemente por el Ministerio de la Vivienda". 7

En este último argumento residía el motivo principal subyacente tras la mayor parte de las modificaciones introducidas en el Plan de 1965, el ambicioso Proyecto Castro Novo, consistente en la ampliación de la ciudad hacia el sur, en el entorno del promontorio de Cotolino, que separa la ensenada de Brazomar de la de Mioño, definido en el PGOU como el área de "expansión natural del Municipio" (Delgado, 2011).

5 Archivo Municipal de Castro Urdiales, Leg. 701, Acta de la sesión de 17 de septiembre de 1966. La cursiva, de aquí en adelante, es de la autora.

6 Archivo Municipal de Castro Urdiales, Leg. 701, Acta de la sesión plenaria de 21 de enero de 1972.

7 Archivo Municipal de Castro Urdiales, Leg. 701, acuerdo plenario de 27 de octubre de 1976 
Para legalizar la futura construcción, el Ayuntamiento aprobó en 1976 nuevas modificaciones del PGOU y se elaboraron cuatro Planes Parciales que fueron aprobados definitivamente el 28 de noviembre de 1977. Se encargó al Taller de Arquitectura dirigido por Ricardo Bofill ${ }^{8}$ un Proyecto de Urbanización, aprobado en octubre de 1978, que afectaba a una superficie de casi un millón de metros cuadrados sobre la que iban a construirse unas 5000 viviendas para, en palabras del propio arquitecto encargado del diseño, dar respuesta a las necesidades de descongestión del Gran Bilbao.

El proyecto suscitó una gran polémica, hasta el punto de que la movilización ciudadana forzó la celebración de una consulta popular, tal vez la primera en España en relación con una actuación urbanística, en la que más de la mitad de la población manifestó su oposición. Este hecho, unido a problemas de financiación, obligó a la sociedad promotora a abandonar el proyecto.

El frustrado Proyecto Castro Novo puede ser considerado como un precedente de la espectacular transformación funcional y urbanística que iba a experimentar Castro Urdiales inmediatamente después. Porque en el municipio se ha generado suelo urbano y urbanizable equivalente al programado para el Proyecto Castro Novo "multiplicado por diez, con el agravante de que este crecimiento urbanístico no ha venido acompañado de los equipamientos y servicios que necesita la población actual de Castro Urdiales". 9

\section{La consolidación de las actividades de servicios como base de la economía castreña}

La segunda década del siglo XX fue testigo del declive de la actividad minera al tiempo que se iniciaba la vigorización de las actividades vinculadas a lo que hoy llamaríamos el turismo residencial, el veraneo de la burguesía, en particular bilbaína, emparentada con las actividades mineras e industriales castreñas. Pero fue a lo largo de los años sesenta y setenta de la pasada centuria cuando se produjo la transformación definitiva de la economía de Castro Urdiales como consecuencia de su afianzamiento como núcleo turístico para capas cada vez más amplias de población. ${ }^{10}$ El carácter terciario que ha adquirido desde entonces la base económica del municipio parece incuestionable a la luz de los datos de la distribución por sectores de la población activa y de las empresas censadas (Figura 4).

8 Ricardo Bofill había presentado con anterioridad el Proyecto Castro Novo, en febrero de 1977, con la intención de construir 5000 viviendas permanentes para 25000 personas en una superficie de un millón de metros cuadrados y con una inversión de unos 15000 millones de pesetas.

9 Otro Castro es posible, 16 de noviembre de 2009.

10 Un proceso similar al que se produce de forma coetánea en otras villas del litoral cantábrico (Beascoechea, 2017). 
Figura 4. Composición de la población activa (2016) y los establecimientos empresariales (2015).

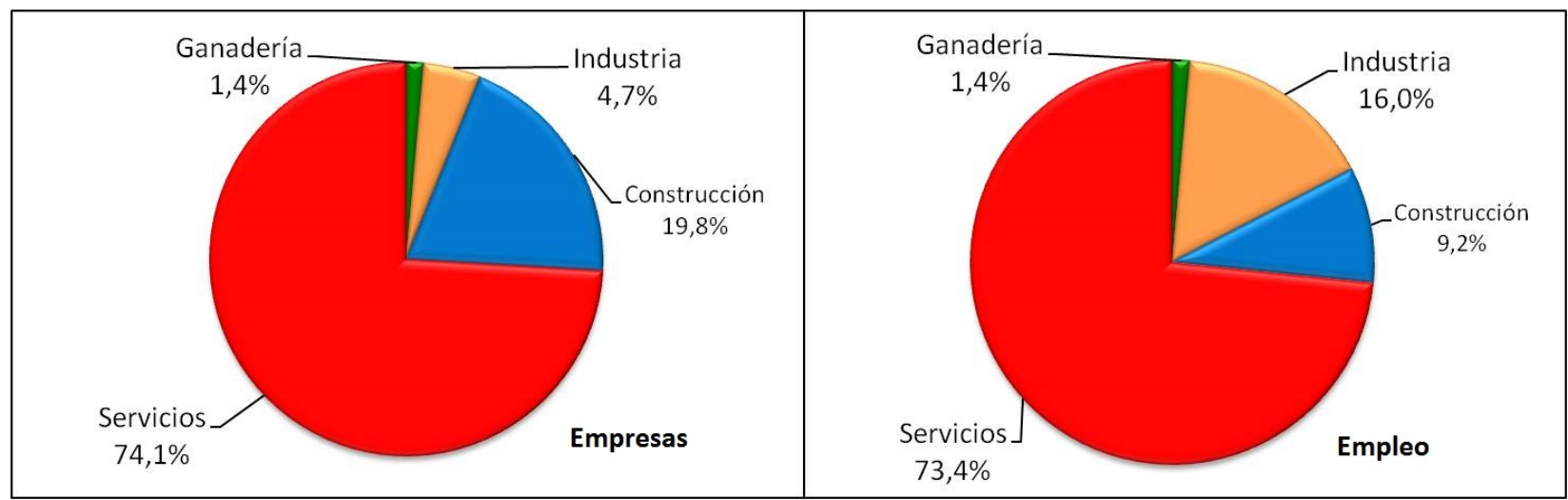

Fuente: elaboración propia a partir de datos del INSS e ICANE actualizados a 7 de abril de 2017

Entre los residentes afiliados a la Seguridad Social en 2016 tienen absoluta primacía los empleados en el sector servicios (4647 personas, 73,4\%), seguidos muy de lejos por los ocupados en actividades industriales y mineras (1014 afiliados, 16,0\%). Son valores que se corresponden con bastante exactitud con los referidos a las empresas empleadoras: en 2015 el 74,1\% de las censadas en el municipio correspondían al sector servicios en tanto que las industriales no eran nada más que 4,7\%. Es preciso también destacar el relevante papel desempeñado por el sector de la construcción pese a la gran reducción sufrida tras el estallido de la "burbuja inmobiliaria".

La pesca, componente esencial de la base económica durante siglos, es hoy una actividad casi anecdótica. A mediados de 2011 el puerto de Castro Urdiales contaba con un sólo barco de cerco con dimensiones suficientes para dedicarse a la pesca de altura y once pequeños pesqueros de bajura. Medida en términos de producción, el volumen de pesca desembarcada se ha reducido drásticamente pasando de 1716 tm/año de capturas entre 1987 y 1992 a 495,8tm en 2012 (Instituto Cántabro de Estadística, ICANE).

La actividad industrial sigue teniendo todavía alguna relevancia, como lo atestigua la existencia en 2015 de ochenta empresas y noventa y nueve establecimientos dedicados a las actividades de transformación (CAMERDATA), en general de muy pequeñas dimensiones (el 84 \% de ellas tienen menos de diez empleados). Entre ellas destacan las industrias manufactureras, rama a la que corresponde casi la mitad de las empresas industriales. Además de las metalúrgicas, un porcentaje muy elevado de las industrias manufactureras se orienta a la elaboración de productos alimentarios, en particular y siguiendo la tradición, a la elaboración de conservas de pescado; son estas industrias, por otro lado, las que ocupan mayor cantidad de mano de obra.

En el sector servicios, el fundamental en la actualidad, tienen especial importancia dos subsectores, el comercial y el turístico. 
El primero se apoya en 2015, en 436 empresas la mayor parte de las cuales (75 \%) se dedican al comercio al por menor. La importancia de este subsector y su composición ponen de manifiesto la magnitud de la función cumplida por la ciudad para atender a su propia población y a la clientela de un área de influencia comarcal relativamente amplia. Porque, si bien el comercio al por menor de productos alimenticios tiene un puesto relevante en la estructura comercial $133,8 \%$ de las empresas minoristas), es imprescindible destacar el mayor peso del comercio al por menor de productos no alimenticios $(65,7 \%)$.

Las actividades relacionadas con el turismo han alcanzado en la actualidad una gran importancia. Según los datos proporcionados por el Directorio de Establecimientos Turísticos de la Dirección General de Turismo del Gobierno de Cantabria, en 2012 se contabilizaban 2964 plazas de alojamiento distribuidas entre diecinueve hoteles, hostales y pensiones y tres campings. El equipamiento hostelero consistía, en la misma fecha, en sesenta y cuatro restaurantes, dieciséis cafeterías y ciento noventa y seis bares; a ellos hay que añadir siete agencias de viaje y tres empresas de turismo rural. En 2015, de acuerdo con los datos proporcionados por ICANE, hay dieciocho empresas orientadas a proporcionar servicios de alojamiento y doscientas veinte de servicios de comidas y bebidas.

La primacía del comercio y los servicios de ocio no puede ocultar la presencia de un elevado número de otros vinculados a la economía productiva, como los servicios financieros y a las empresas, los inmobiliarios, etc., que, junto a una apreciable cantidad de servicios públicos, nutren la función terciaria que la ciudad desempeña.

No obstante, la potencialidad turística del municipio no queda bien reflejada sólo a través de los indicadores que se han venido detallando porque dichas actividades tienen en Castro Urdiales otra forma fundamental de producirse, la residencial. Es lo que explica la existencia en 2011 de 8614 viviendas secundarias; cuantía a la que se ha llegado en muy poco tiempo. Por otra parte, la población vinculada total que figuraba en dicho Censo ascendía a 48968 personas de las cuales 14849 (88,7\% de la población no residente) era población vinculada por pernoctar en el municipio más de catorce noches al año por tener allí una segunda vivienda. Otras estimaciones arrojan cifras muy similares: la población estacional, que alcanza su volumen máximo en el verano, se encuentra entre 56000 y 62000 personas en el mes de agosto. ${ }^{11}$

La edificación en muy poco tiempo de un elevado número de viviendas explica que la construcción haya sido hasta hace poco el segundo sector de actividad en orden de importancia en la economía castreña. En diciembre de 2007, en el momento álgido de la "fiebre constructora", estaban

11 La Encuesta de Infraestructura y Equipamientos Locales de 2015 (Ministerio de Hacienda y Administraciones Públicas) calcula la población estacional máxima de Castro Urdiales en 60710 habitantes, cifra que considero muy inferior a la realidad ya que esa es, prácticamente, la población habitual real del municipio. 
afiliados en el Régimen General de la Seguridad Social en el sector de la construcción 1.201 trabajadores castreños, que representaban el 17,6\% de la población activa. Todavía en el primer semestre de 2009, iniciada ya la crisis, permanecían afiliadas 851 personas (13,3\% de la población activa total) distribuidas en las 421 empresas aquí radicadas. Los valores han disminuido bastante en fechas posteriores hasta llegar a 583 afiliados en el sector (9,2 \% de la población activa) en 2016.

\section{El extraordinario incremento de la movilidad residencial y de la población}

Desde comienzos de la última década del siglo XX Castro Urdiales ha iniciado una nueva fase en su evolución demográfica estimulada por la integración funcional plena en la aglomeración metropolitana de Bilbao (Figura 5).

La población empezó a crecer moderadamente a lo largo los años ochenta hasta recuperar en 1992 el volumen que había alcanzado a comienzos del siglo XX. El ascenso poblacional ha continuado de forma casi ininterrumpida hasta la actualidad, de manera que entre 1996 y 2016 la población castreña se ha más que duplicado (110,3 \%) pasando de poco más de 15000 a casi 32000 personas empadronadas. El ritmo de la variación interanual se ha acelerado progresivamente desde mediados de los años noventa hasta alcanzar 7,2 \% entre 2004 y 2005. Desde entonces ha ido disminuyendo hasta la actualidad, aunque manteniendo valores por encima de $3 \%$ anual hasta 2008.

Figura 5. El crecimiento reciente de la población de Castro Urdiales

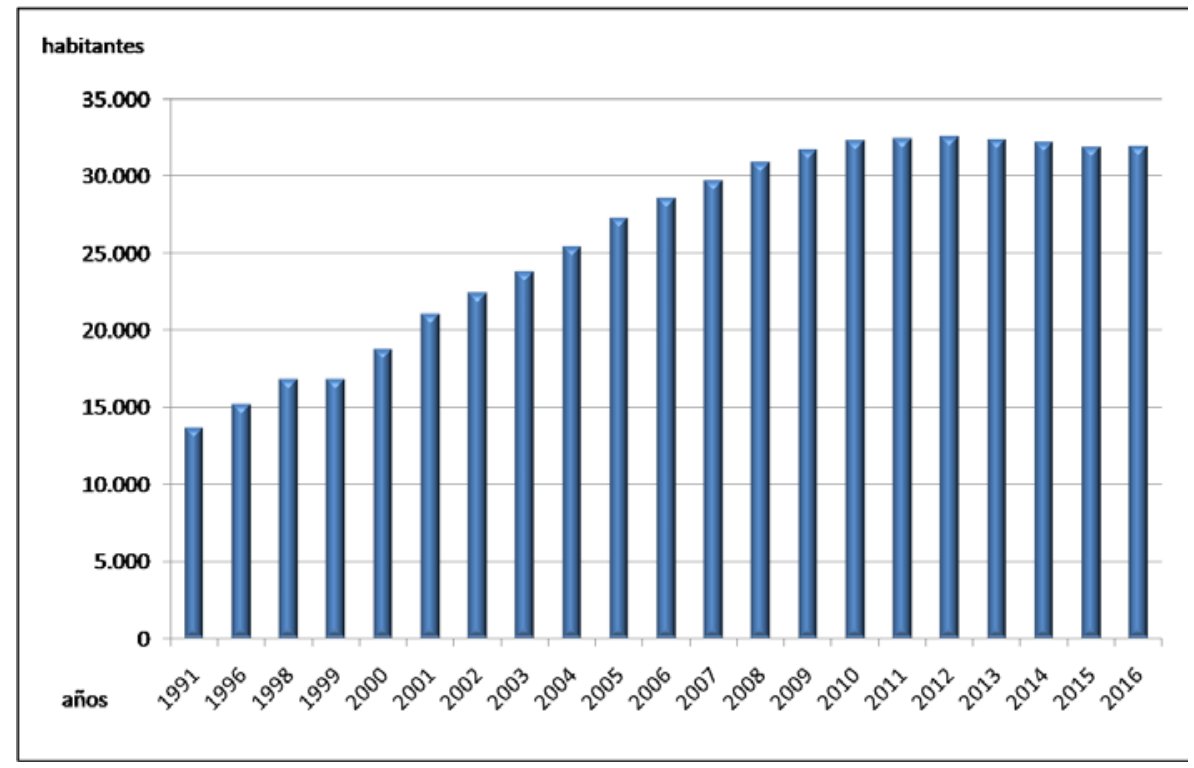

Fuente: elaboración propia a partir de los Padrones de Población (INE, 1991-2016)

El componente principal del crecimiento demográfico ha sido el saldo migratorio, que ha aportado 3491 nuevos habitantes en los once años transcurridos de 2005 a 2015 (Figura 6). En este 
balance, el integrante esencial ha sido la migración interior (61,2\%), aunque la extranjera haya traído a la ciudad en ese plazo a 1356 habitantes. La inmigración ha tocado fondo a partir de 2010; desde ese año los saldos han comenzado a ser negativos en ambas modalidades, si bien se percibe una leve recuperación en 2015 y 2016, en particular en lo que se refiere a la inmigración extranjera.

La forma específica de crecimiento de la población castreña se expresa con plena claridad en la procedencia de sus habitantes según el lugar de nacimiento. En 2016 menos de un tercio de la población, 32,4 \%, ha nacido en el propio municipio frente al 52,6 \% de personas nacidas en otra Comunidad Autónoma, 10,3\% en el extranjero y sólo 4,7 \% en otros municipios de Cantabria. La mayor parte de los habitantes nacidos en otra Comunidad Autónoma provienen del País Vasco; en este aspecto puede servir como referencia que en mayo de 2009 estaban censadas 11352 personas procedentes de la vecina Comunidad Autónoma (35,5 \% de la población municipal), la mayoría de ellas (10957) originarias de Vizcaya. Valores que, al referirse únicamente a la población empadronada, quedan muy por debajo de la realidad ya que la práctica totalidad de la población no censada proviene del País Vasco, lo que permite suponer que más de la mitad de los residentes reales de Castro Urdiales tengan hoy en día esa procedencia.

\section{Figura 6. Evolución reciente del saldo migratorio}

\section{del municipio de Castro Urdiales (2005-2015)}

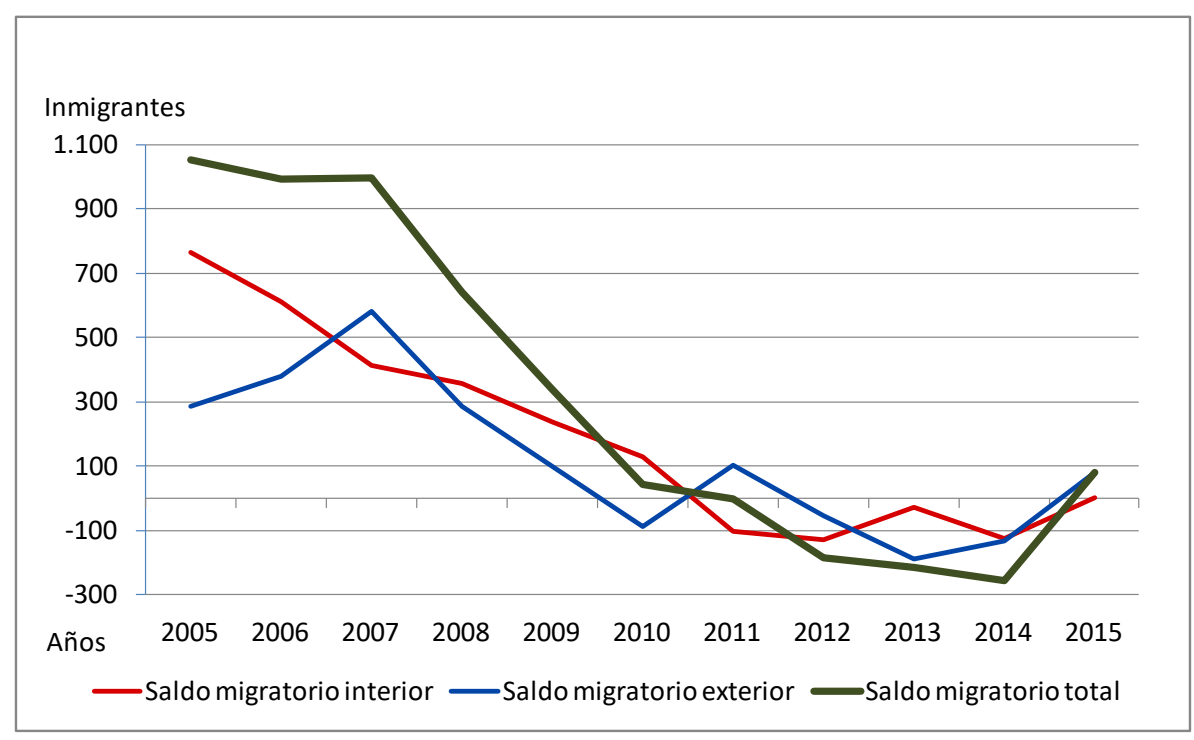

Fuente: elaboración propia a partir de (INE, 2005-2015)

Aunque la cuantía absoluta sea inferior, el crecimiento vegetativo ha ido adquiriendo cada vez mayor importancia en el incremento poblacional ya que se ha pasado de un saldo biológico negativo a mediados de años noventa a un crecimiento natural por encima de cien personas cada año entre 2003 y 2013 (Figura 7). Las causas de este cambio se encuentran en el continuo 
aumento del número de nacimientos, mucho más rápido que el de defunciones, que se ha estabilizado en valores bajos, de modo que la diferencia entre una y otra cifra ha sido cada vez más amplia hasta hace poco tiempo.

El radical cambio de signo del movimiento natural viene de la mano de la modificación de la estructura por edades, lo que resulta evidente si consideramos los valores relativos, las tasas de natalidad y mortalidad. La primera ha crecido sensiblemente: hasta finales del siglo XX permanecía levemente por debajo de diez por mil; a partir de 1999 ha rebasado ampliamente ese umbral situándose por encima de trece por mil en el primer lustro del siglo XXI (15,4\%o en 2005), si bien en la actualidad ha vuelto a retroceder por debajo de ocho por mil a mediados de la segunda década de la presente centuria (7,2\%o en 2015). Por el contrario, la tasa de mortalidad ha descendido desde cerca de once por mil en 1996 hasta estabilizarse entre seis y siete por mil desde 2004 (5,9\%o en 2013). En consecuencia, el crecimiento vegetativo, levemente negativo todavía en 1996, es hoy claramente positivo hasta superar el cinco por mil anual desde 2004; esas cifras también están disminuyendo en la actualidad, aunque conservando todavía su carácter positivo (3,2\%o en 2013 y $1 \%$ en $2014-2015)$.

Figura 7. El movimiento natural de la población de Castro Urdiales (1996-2015)

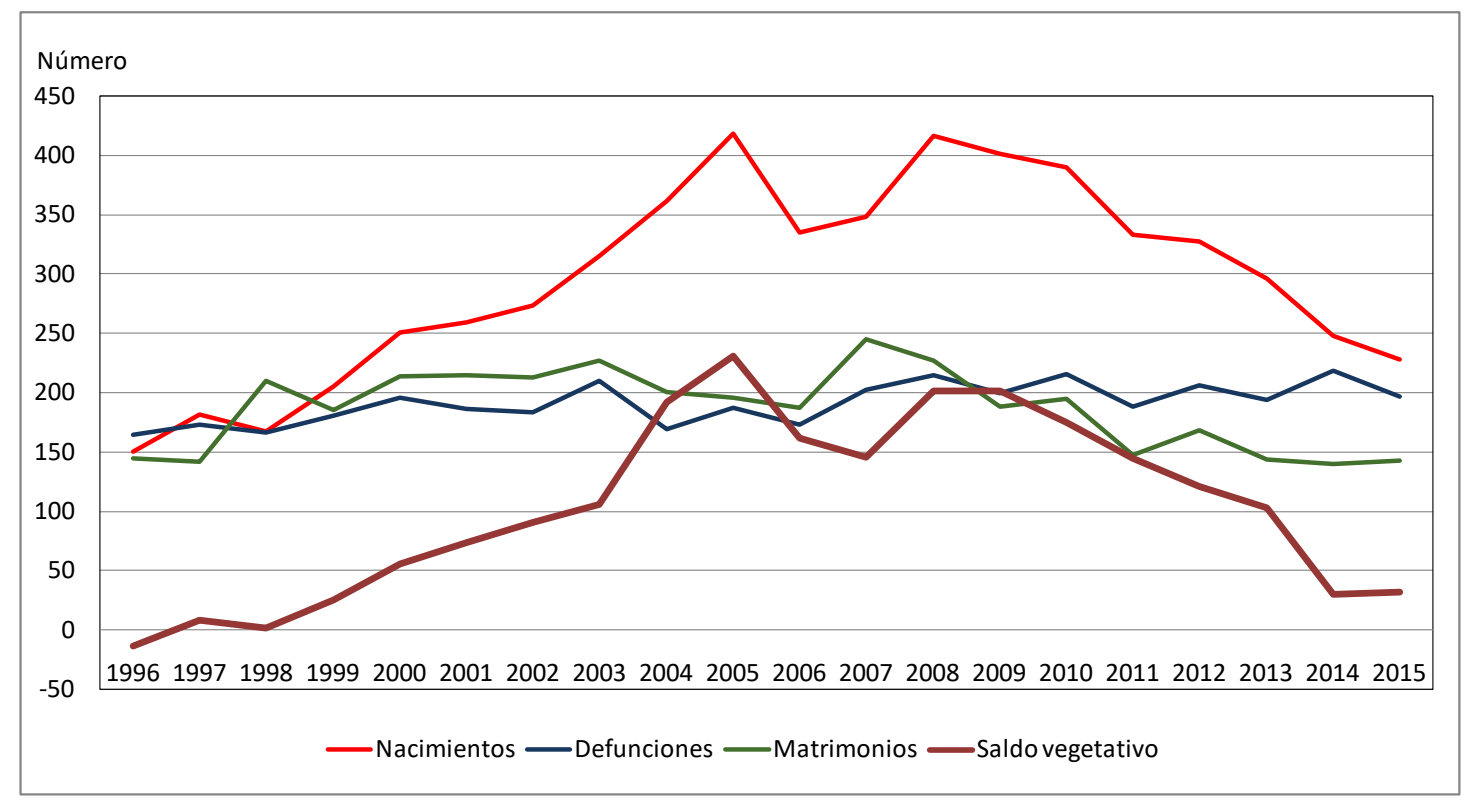

Fuente: elaboración propia a partir del Movimiento Natural de Población (INE, 1996-2015)

La notable dinamización demográfica que reflejan los datos anteriores hay que relacionarla con el rejuvenecimiento de la población castreña, también reciente. En veinte años, entre 1996 y 2016, se han producido visibles cambios en cuanto a la estructura biológica de la población, en particular en lo que se refiere a su composición por edad. 
Figura 8. Evolución reciente de la estructura biológica de la población de Castro Urdiales
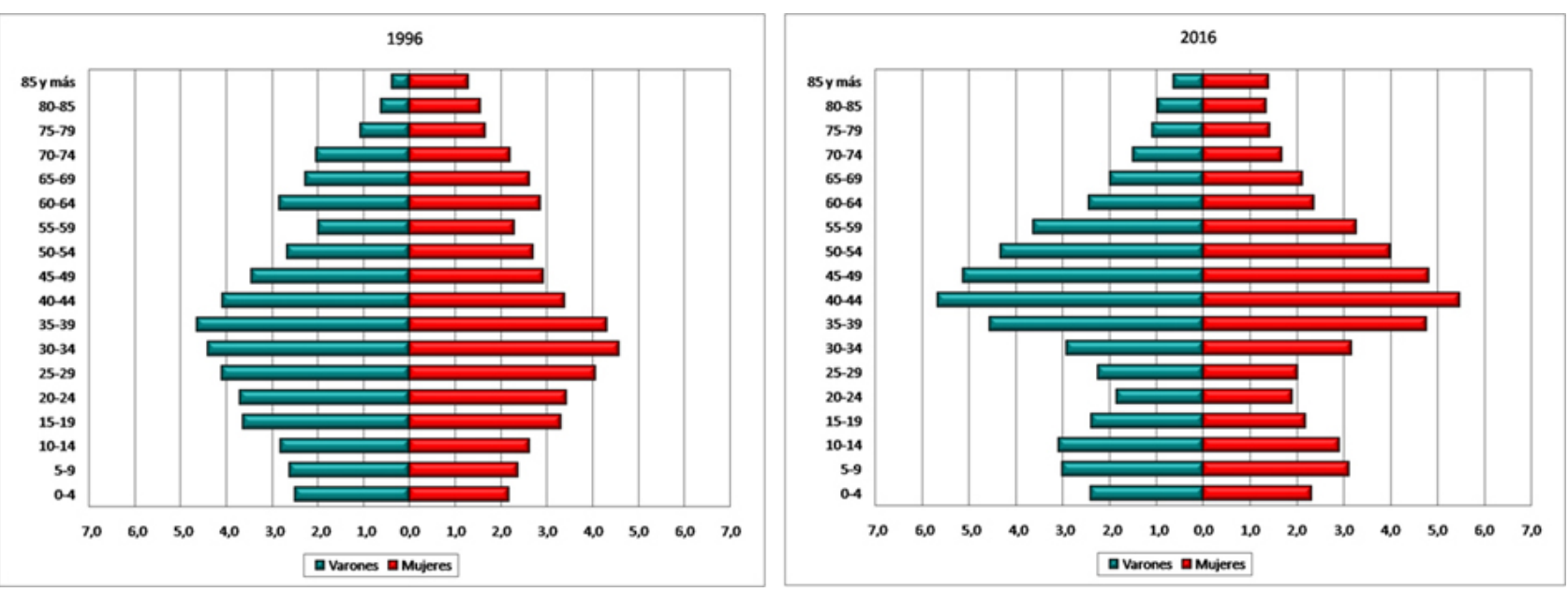

Fuente: elaboración propia a partir de los Padrones de Población (INE, 1996, 2016)

En primer lugar, ha disminuido levemente la proporción de mayores de 65 años, que ha pasado de ser $15,6 \%$ del total en la primera fecha a $14,1 \%$ en la segunda. Aunque es cierto que el porcentaje de la población infantil y juvenil, con menos de 20 años, se ha reducido algo (de $22,0 \%$ a 21,4\%), esa rebaja es imputable sólo a los jóvenes de 10 a 20 años (de 12,4 \% a $10,5 \%$ ) en tanto que la proporción de los menores de esa edad, los nacidos durante la primera década del siglo actual, ha subido de $9,6 \%$ a 10,8 \% a causa del aumento de la natalidad en esos años.

La comparación de las pirámides de población de las dos fechas referidas no deja lugar a dudas (Figura 8). A simple vista se percibe el alargamiento de algunas cohortes de la base, las que representan a los más jóvenes, y de las centrales, las correspondientes a los adultos de entre 35 y 50 años, protagonistas principales de la inmigración interior y exterior.

En correspondencia con lo anterior, la tasa de envejecimiento, con un valor de 14,1\% en 2016, está entre las más bajas de Cantabria (la media regional es 20,7\%), en tanto que, por el contrario, la tasa de juventud, que en 2016 es 16,8\%, se encuentra entre las más altas de la región (13,6\% de media).

\section{La problemática vinculada al crecimiento reciente de la población}

Algunos de los problemas más importantes con que se enfrenta hoy Castro Urdiales derivan del apresurado crecimiento reciente de la población y de la gran diferencia existente entre la población residente de hecho y la población censada formalmente. Esta circunstancia suele ser considerada como una de las causas principales de debilidad de las finanzas municipales (Hortas-Rico, 2014) puesto que el Fondo de Financiación Municipal se rige por el criterio de la población censada en 
tanto que los gastos del municipio dependen de la población real, que es la que demanda y usa los servicios municipales, esté empadronada o no.

En la actualidad las cifras reales de población estimada superan con mucho a las proporcionadas por censos y padrones ya que se calcula que realmente vive en Castro Urdiales, aunque no estén empadronados allí, casi el doble de los habitantes censados oficialmente. Según la empresa encargada del servicio de agua (ASCAN), el municipio tiene un consumo permanente equivalente al de una población de 65000 habitantes y los datos que obran en poder del Ayuntamiento, referidos al cobro de impuestos, elevan esa cuantía a unos $70000 .^{12}$

El origen de esta problemática está relacionado con el tipo de crecimiento reciente de la población de Castro Urdiales, el primero de los cuales consiste, como se ha expuesto antes, en la llegada de nuevos residentes procedentes de otros territorios, en particular del País Vasco, donde suelen permanecer inscritos. Esta situación explica que en 2003 se adoptaran algunas medidas para incentivar el empadronamiento, como facilitar tarifas reducidas para el uso de equipamientos y servicios municipales o dotar con una subvención de $150 €$ a los recién nacidos registrados en el juzgado y de $200 €$ a los menores de dieciséis años empadronados con su padre, madre o tutor. La iniciativa fue un absoluto fracaso ya que los principales motivos aducidos para no censarse allí se refieren a las condiciones fiscales y de prestación de servicios, en particular los sanitarios, consideradas más beneficiosas en el País Vasco que las que se ofrecen en Cantabria.

El déficit de ingresos municipales origina un "círculo vicioso" patente en carencias en cuanto a equipamientos y servicios, que han sido una preocupación constante en la vida de la ciudad desde hace varias décadas, en particular por lo que se refiere a la sanidad, la educación y el abastecimiento de agua.

La asistencia sanitaria ha adolecido habitualmente de falta de recursos para atender a una población censada de más de 30000 personas, que se duplica si se suman las no empadronadas. Para paliar el problema, en 2009 se abrió un nuevo centro de salud situado en el barrio de mayor crecimiento poblacional, Cotolino, lo que no impidió que el centro preexistente, ubicado en el centro urbano y con peores instalaciones, siguiera estando absolutamente desbordado. La solución no ha llegado aún y sólo recientemente se ha vuelto a proponer la ampliación del centro Cotolino II y la creación de un centro de especialidades periféricas.

12 Un Informe de la Concejalía de Hacienda en respuesta al Informe del Tribunal de Cuentas, de 3 de octubre de 2008, alegaba que "Dado que por cada habitante no censado dejábamos de cobrar la cantidad correspondiente proveniente de la participación en los impuestos tributarios del Estado, que en el año 2004 suponía la cantidad de 128 euros por habitante, el impacto económico anual se estima en 3,1 millones de euros sólo para el año 2004." En la actualidad se calcula que la pérdida de ingresos municipales por este motivo asciende a unos cinco millones de euros anuales (Verano, 2016, May 26). 
Por otra parte, durante un período de tiempo estuvo vigente un convenio entre los gobiernos autonómicos de Cantabria y el País Vasco para proporcionar atención sanitaria especializada a la población castreña por parte del Servicio Vasco de Salud. Con motivo de la finalización del acuerdo, a principios de 2011, se resaltó de forma reiterada que la atención sanitaria castreña sufría "un grave deterioro que tiene mucho que ver con los habitantes vascos en el municipio" sin empadronar (Ruiz, 2011, February 2). ${ }^{13}$

Las carencias de los servicios educativos no van a la zaga. El Sindicato de Trabajadores de la Enseñanza de Cantabria (STEC) alertó en 2011 del "grave problema de escolarización" que hay en Castro Urdiales, calificando de "explosiva" la situación del municipio en el que "no hay suelo ni proyecto de construcción del nuevo colegio, ni se han iniciado las obras del instituto de Secundaria que se necesitan urgentemente desde hace varios años" (EFE, 2011, June 1). Tres años más tarde un partido político de reciente creación, CastroVerde, presentó un informe, basado en datos oficiales, en el que se ponía de manifiesto la gravedad del estado de la enseñanza y la urgencia de construir un sexto colegio de enseñanza primaria y un tercer centro de secundaria. Finalmente, a principios de 2016 se puso en funcionamiento el tercer instituto de enseñanza secundaria.

Durante años el abastecimiento de agua ha sido insuficiente y de mala calidad para atender en el verano a la población, incluso en años de abundantes precipitaciones. Hasta 2013 no se aprobó la construcción de un nuevo depósito de agua para satisfacer las necesidades de la voluminosa población residente en Cotolino, pero todavía no ha sido construido. No obstante, los problemas más acuciantes han empezado a resolverse a raíz de la puesta en funcionamiento del bitrasvase Ebro-Besaya-Pas y de la conducción de la infraestructura conocida como "Autovía del Agua" iniciada en 2004 y completada en noviembre de 2016.

Asimismo, la integración funcional, residencial y laboral, de Castro Urdiales con Bilbao está generando graves problemas de conectividad entre ambas ciudades, cuya proximidad permite que una importante proporción de residentes en Castro Urdiales se traslade diariamente a Bilbao por motivos de trabajo, estudios, uso de servicios, compras, ocio, etc.

Se calcula que unos 45000 vehículos se desplazan cada día entre Castro Urdiales y Vizcaya por la autovía A-8; un aforo que se duplica durante los fines de semana, "puentes" e inicio y final de los períodos vacacionales. Este hecho se manifiesta también en el notable incremento reciente del parque castreño de vehículos: los turismos censados en el municipio han pasado de 8791 en 2003

13 “En Castro están censadas 32751 personas, aunque el Ayuntamiento considera que cuenta con una población real de unos 70000 habitantes. En consecuencia, los servicios públicos, preparados para la población contabilizada por el padrón, se ven superados cuando deben atender al doble de vecinos" (San Miguel, 2011, April 17). A principios de 2012 el Gobierno cántabro solicitó al vasco la continuidad de la asistencia "recíproca", la recuperación de la doble dirección y el restablecimiento de la situación anterior al 1 de enero de 2011 (EFE, 2012 , February 3). 
a 14188 en 2016 (61,4\%) al tiempo que el número de habitantes por vehículo ha disminuido de 2,7 a 1,7 (-38 \%) en el mismo plazo de tiempo (ICANE).

En el gran volumen de desplazamientos intrametropolitanos hay que incluir también los realizados a través de los autobuses de línea que, con una elevada frecuencia (cada media hora), realizan 28 viajes y transportan a unas 2.000 personas al día. ${ }^{14}$

Para descongestionar el tráfico de la autovía A-8 se propuso la construcción de un tercer carril para evitar los atascos y retenciones que se producen continuamente. Pero esta posibilidad fue descartada por razones económicas con la expectativa de que la apertura de la Variante Sur Metropolitana de Bilbao, conocida como "Supersur", la nueva autovía de circunvalación de Bilbao terminada en 2015, contribuyera a paliar el problema y se pudiera posponer la costosa obra.

Entre tanto se adoptó el recurso de habilitar un carril reversible en el tramo de treinta y un kilómetros de la autovía, desde Ugaldebieta a Liendo, considerado como uno de los tramos más conflictivos de toda la red viaria cantábrica. La alternativa resultó bastante discutible, generando incluso situaciones de tensión entre los gobiernos de las dos Comunidades Autónomas implicadas, por lo que también fue desechada.

Además de éstas, entre las posibilidades que se han barajado están la de recuperar la antigua línea de ferrocarril de Traslaviña entre la localidad cántabra y Bilbao, en desuso desde 1966, la ampliación de la línea del "Metro" vizcaíno desde Santurce, la prolongación de la actual línea de FEVE o la apertura de un nuevo trazado de RENFE desde Muskiz hasta la localidad cántabra (Uriona, 2010, April 28). La opción de unir ambas ciudades a través de la línea de cercanías de ADIF parece que era la predilecta, si bien la inversión necesaria, calculada en 317 millones de euros, ha sido un obstáculo insuperable hasta el momento.

La presencia masiva de residentes de origen vasco no ha provocado hasta ahora ningún tipo de fracturas importantes entre los habitantes autóctonos y los nuevos residentes, pero sí ha generado significativos desencuentros. Sirvan como ejemplo las reticencias y la polémica suscitadas por la creación, en agosto de 2008, de la Agrupación Vasca de Castro Urdiales "Castro bai" ("Castro sí"). El proyecto tuvo una duración efímera, sin embargo, dos años más tarde, se fundó un partido político denominado, expresivamente, "Anexión a Vizcaya", e integrado sobre todo por vecinos del barrio de Cotolino. Este partido se presentó a las elecciones municipales de mayo de 2011 con el objetivo de "defender el municipio y los intereses vecinales: los problemas reales en el

14 Desde hace varios años la línea de autobuses que une Castro Urdiales con Bilbao se encuentra colapsada a pesar de tener una gran frecuencia (Gude, 2011, October 10; Verano, 2017, April 6). 
municipio" (Verano, 2010, September 13). ${ }^{15}$ En esa convocatoria el partido reunió 809 votos (6\%) y obtuvo un concejal, logros que repitió en las elecciones municipales de 2015.

\section{Especialización en la función residencial y modificación de las formas de uso del suelo}

En Castro Urdiales se ha construido una gran cantidad de viviendas desde la última década de los años noventa del siglo XX hasta el estallido de la crisis inmobiliaria a finales de la primera década del actual (Tabla 1 y Figura 9).

Tabla 1. Evolución del parque de viviendas de Castro Urdiales

\begin{tabular}{|c|c|c|c|c|c|c|c|c|c|c|c|c|}
\hline \multirow{2}{*}{ Clase de vivienda } & \multicolumn{2}{|c|}{1991} & \multicolumn{2}{|c|}{2001} & \multicolumn{2}{|c|}{$\begin{array}{c}\text { Variación 1991- } \\
2001 \\
\end{array}$} & \multicolumn{2}{|c|}{2011} & \multicolumn{2}{|c|}{$\begin{array}{c}\text { Variación } \\
\text { 2001-2011 }\end{array}$} & \multicolumn{2}{|c|}{$\begin{array}{l}\text { Variación 1991- } \\
2011 \\
\end{array}$} \\
\hline & $\mathrm{N}^{\circ}$ & $\%$ & $\mathrm{~N}^{\circ}$ & $\%$ & $\mathrm{~N}^{\circ}$ & $\%$ & $\mathrm{~N}^{\circ}$ & $\%$ & $\mathrm{~N}^{\circ}$ & $\%$ & $\mathrm{~N}^{\circ}$ & $\%$ \\
\hline Viviendas principales & 4018 & 44,1 & 8209 & 43,6 & 4191 & 104,3 & 13617 & 53,2 & 5408 & 65,9 & 9599 & 238,9 \\
\hline $\begin{array}{l}\text { Viviendas no } \\
\text { principales }\end{array}$ & 5097 & 55,9 & 10612 & 56,4 & 5515 & 108,2 & 11978 & 46,8 & 1366 & 12,9 & 6881 & 135,0 \\
\hline Secundarias & 3224 & 35,4 & 8367 & 44,5 & 5143 & 159,5 & 8614 & 33,7 & 247 & 3,0 & 5390 & 167,2 \\
\hline Desocupadas/Vacías & 1871 & 20,5 & 2154 & 11,4 & 283 & 15,1 & 3364 & 13,1 & 1210 & 56,2 & 1493 & 79,8 \\
\hline Otras & 2 & & 91 & & 89 & & 0 & & -89 & & -2 & \\
\hline Total & 9115 & 100,0 & 18821 & 100,0 & 9.706 & 106,5 & 25595 & 100,0 & 6.774 & 36,0 & 16480 & 180,8 \\
\hline
\end{tabular}

Fuente: elaboración propia a partir de Censos de Población y Vivienda (INE, 1991, 2001, 2011)

Figura 9. Composición del parque de viviendas de Castro Urdiales en 2011 según el año de construcción (1900-2011)

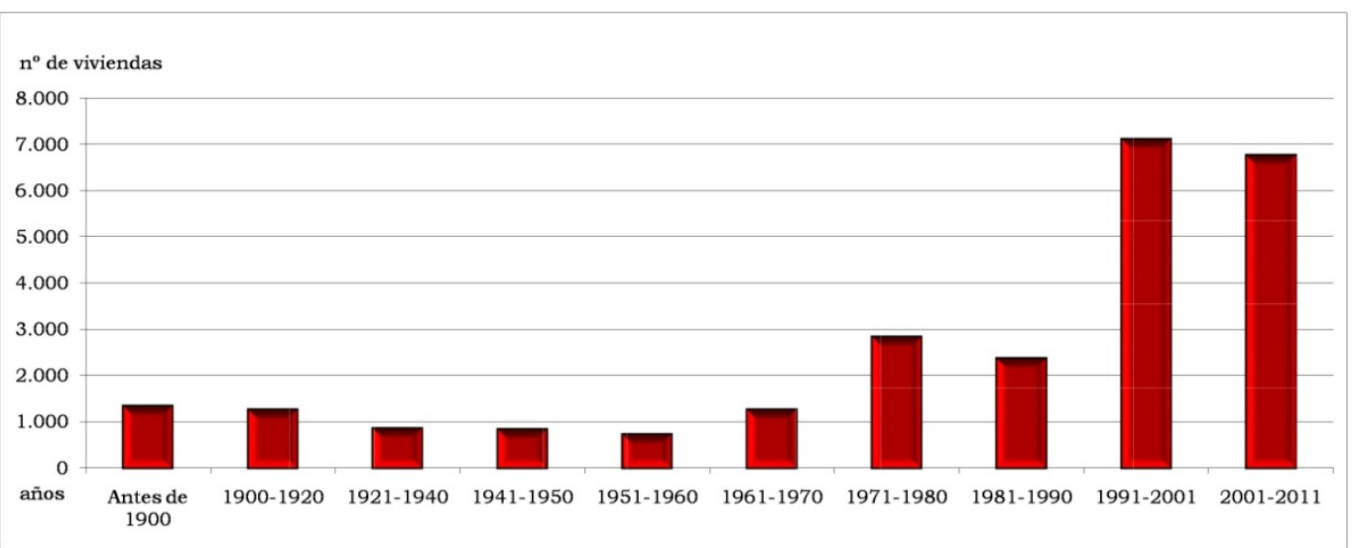

Fuente: elaboración propia a partir de Censos de Población y Viviendas (INE, 2001, 2011)

15 Las aspiraciones reales del partido eran la mejora de las infraestructuras terrestres de unión con Vizcaya, tanto por carretera como por tren, para el desarrollo económico y social de Castro, su integración en la Sanidad de Vizcaya mediante acuerdos de colaboración y la integración en la Diputación de Vizcaya para que los contribuyentes tributen en dicha diputación y se beneficien de los derechos y deberes de los vizcaínos. Tras siete años de existencia el partido se ha disuelto en mayo de 2017 por motivos no explicitados públicamente. 
El parque inmobiliario constaba en 2001 de 18821 viviendas, 9.706 de las cuales, el 51,57\%, habían sido construidas a partir de 1991, lo que significa que el parque se había duplicó en tan sólo diez años. El ciclo constructor se fue acelerando progresivamente durante la última década del siglo XX, una vez superado el primer ciclo de crisis inmobiliaria, hasta alcanzar valores extraordinarios en los años 2000 y 2001 en cada uno de los cuales se construyó un número de viviendas que multiplica por más de dos la cifra de las edificadas en los años anteriores (Figura 10).

\section{Figura 10. Evolución del número de viviendas construidas en Castro Urdiales según el tipo de uso (1991-2001)}

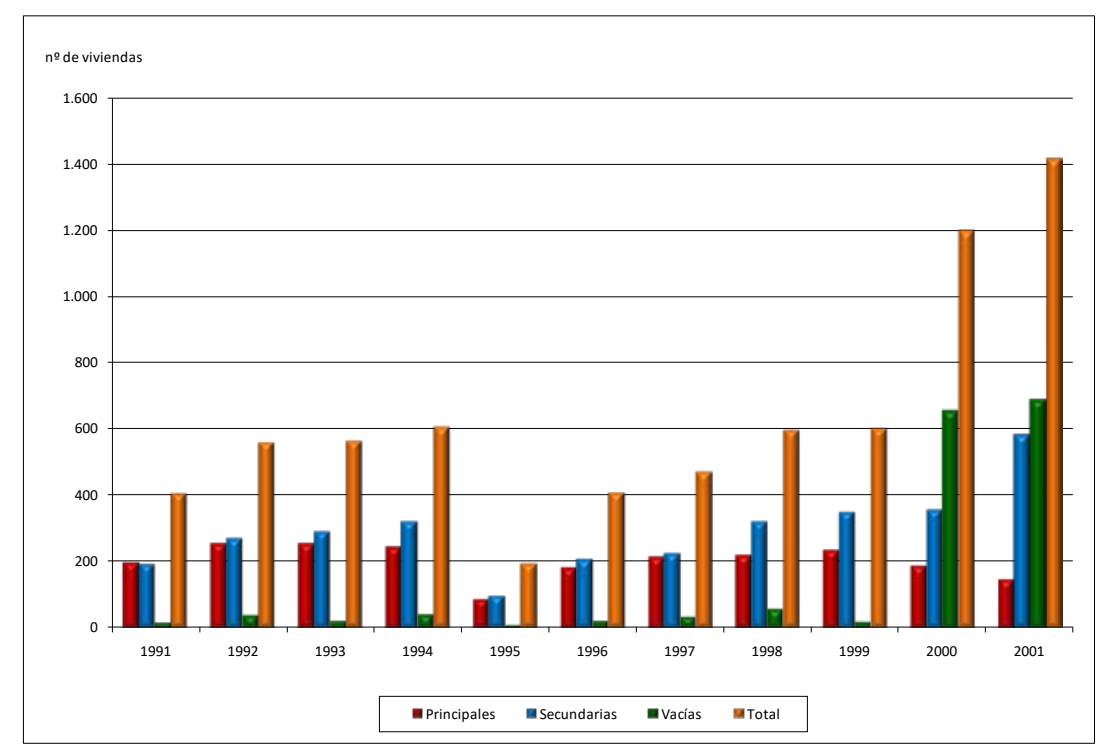

Fuente: elaboración propia a partir del Censo de Población y Viviendas (INE, 2001)

Además del apresurado incremento del volumen de viviendas, al analizar la dinámica constructora es preciso insistir en el uso a que fueron destinadas. Muchas de las nuevas viviendas también tuvieron como destino su uso como residencias principales, aunque fue más elevado aún el número de viviendas secundarias (5143), que son más de la mitad (52,9\%) del total de las construidas entre 1991 y 2001. Un hecho sin parangón en el conjunto regional cuyo parque de viviendas secundarias creció en el mismo plazo 26,4\% mientras que el de Castro Urdiales lo hacía en 159,5\%. Asimismo, resulta elocuente el reducido número de viviendas vacías, salvo en los años 2000 y 2001 que, como es natural, corresponderían a las recién construidas que todavía no se habían puesto en uso.

La especialización de la Marina oriental de Cantabria y, en especial, del término de Castro Urdiales como lugar de ubicación de viviendas vacacionales para la población vasca ha sido reiteradamente puesta de manifiesto (Delgado, 2008; Torres, 2016). Bien es verdad que, con bastante probabilidad, muchas de las viviendas censadas como residencias secundarias, en realidad, ya tenían uso como domicilios permanentes de población no empadronada en el municipio, 
principalmente vasca, que podía adquirir aquí la vivienda a precios muy competitivos en comparación con los de Vizcaya.

El paroxismo edificatorio continuó durante la primera década del siglo XXI, aunque progresivamente desacelerado en el segundo lustro. De acuerdo con los datos del Censo de Viviendas de 2011, el parque de viviendas ascendía en esa fecha a 25595 unidades, de lo que cabe colegir que en los diez primeros años del siglo actual se habían construido otras 6774 viviendas, que representan un incremento de 36\% respecto a las existentes en 2001. De ese conjunto, figuran como no principales (secundarias y desocupadas) 11978 viviendas (46,8\%), frente a 13617 (53,2\%) calificadas como viviendas principales. Según estos datos, parece razonable deducir que había empezado a invertirse la tendencia ya que, por primera vez desde 1991, el porcentaje de viviendas principales es superior al de las secundarias o, al menos, censadas oficialmente como tales (Figura 11).

En resumen, en veinte años, de 1991 a 2011, se han edificado en el término municipal de Castro Urdiales al menos 16480 viviendas, que representan el 180,8\% de las existentes en la primera fecha. Tan impresionante ampliación del parque de viviendas ha supuesto un incremento inmobiliario real que multiplica por más de tres el previsto en el Proyecto Castro Novo, considerado excesivamente ambicioso y rechazado unos años antes.

Figura 11. Evolución de la composición del parque de viviendas de Castro Urdiales según el tipo de uso (1991-2011)

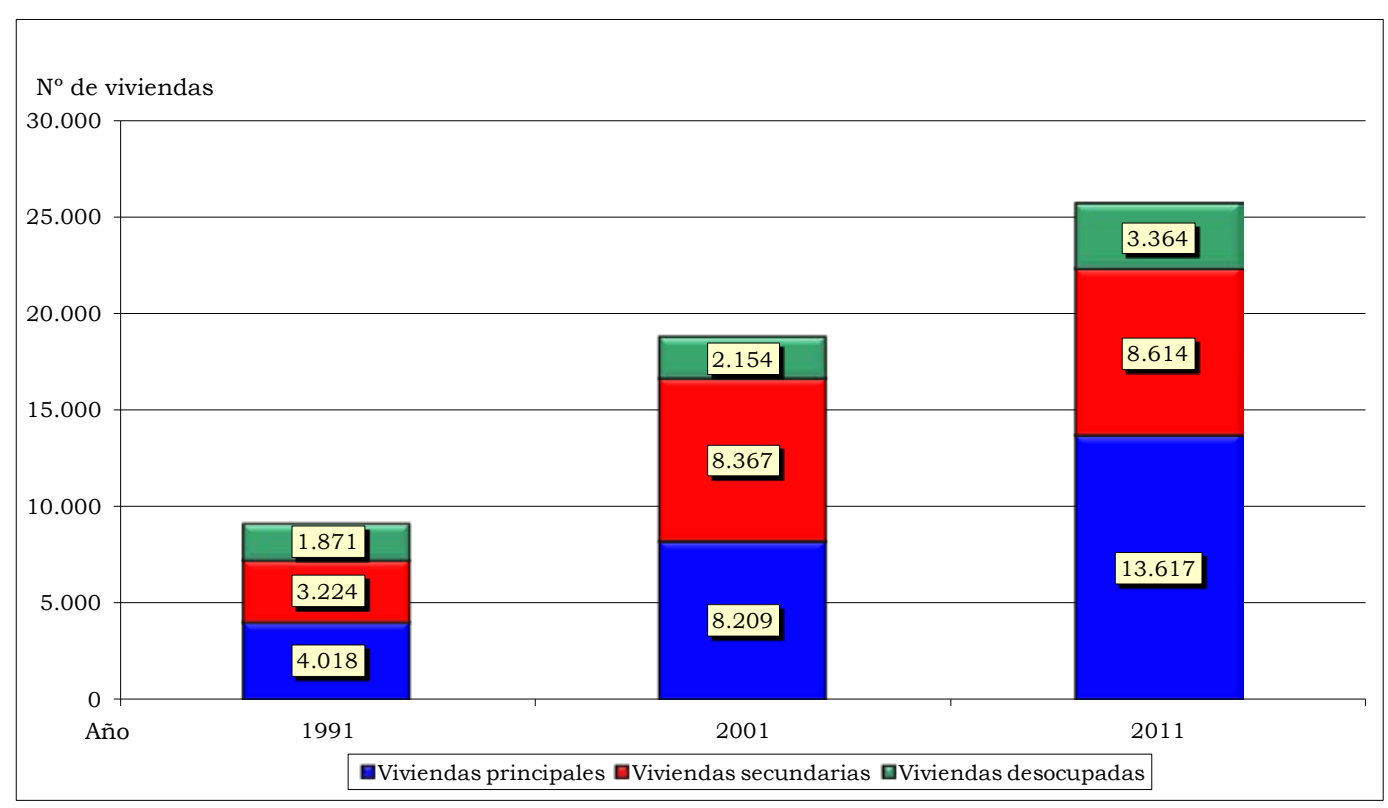

Fuente: elaboración propia a partir de los Censos de Población y Viviendas (INE, 1991, 2001, 2011) 
Sin embargo, resulta sumamente difícil seguir la secuencia de la construcción residencial en Castro Urdiales a partir de 2001. En los datos proporcionados por ICANE faltan para este municipio el número de licencias concedidas para construcción viviendas de 2005 en adelante (Figura 12). Pese a ello, cabe suponer que la construcción prosiguió a buen ritmo si tenemos en cuenta que un Informe de Fiscalización del Tribunal de cuentas (2009) corrobora la importancia de los aprovechamientos urbanísticos, que supusieron en los ejercicios 2004 y 2005 el 18 \% y el $10 \%$, respectivamente, de los ingresos municipales corrientes, alcanzando más de 28,5 millones de euros en 2004 y más de 24,8 millones en 2005 (Tribunal de cuentas, 2009, p. 34). ${ }^{16}$

En aval de esta hipótesis se puede utilizar como indicador indirecto la evolución del volumen de transacciones inmobiliarias. Los datos que proporciona el Ministerio de la Vivienda certifican que la compra-venta de viviendas fue muy intensa hasta el año 2007: en 2004 se realizaron 1173 transacciones, 1178 en 2005, 960 en 2006 y 1050 en 2007. Desde entonces, se produjo una contracción reveladora del impacto que aquí también está teniendo la crisis inmobiliaria: en 2012 sólo se hicieron 261 operaciones si bien el mercado parece haberse reactivado en los dos últimos años de forma que en 2015 se han realizado 399 nuevas transacciones.

Figura 12. Evolución de la construcción de viviendas (visados y licencias)

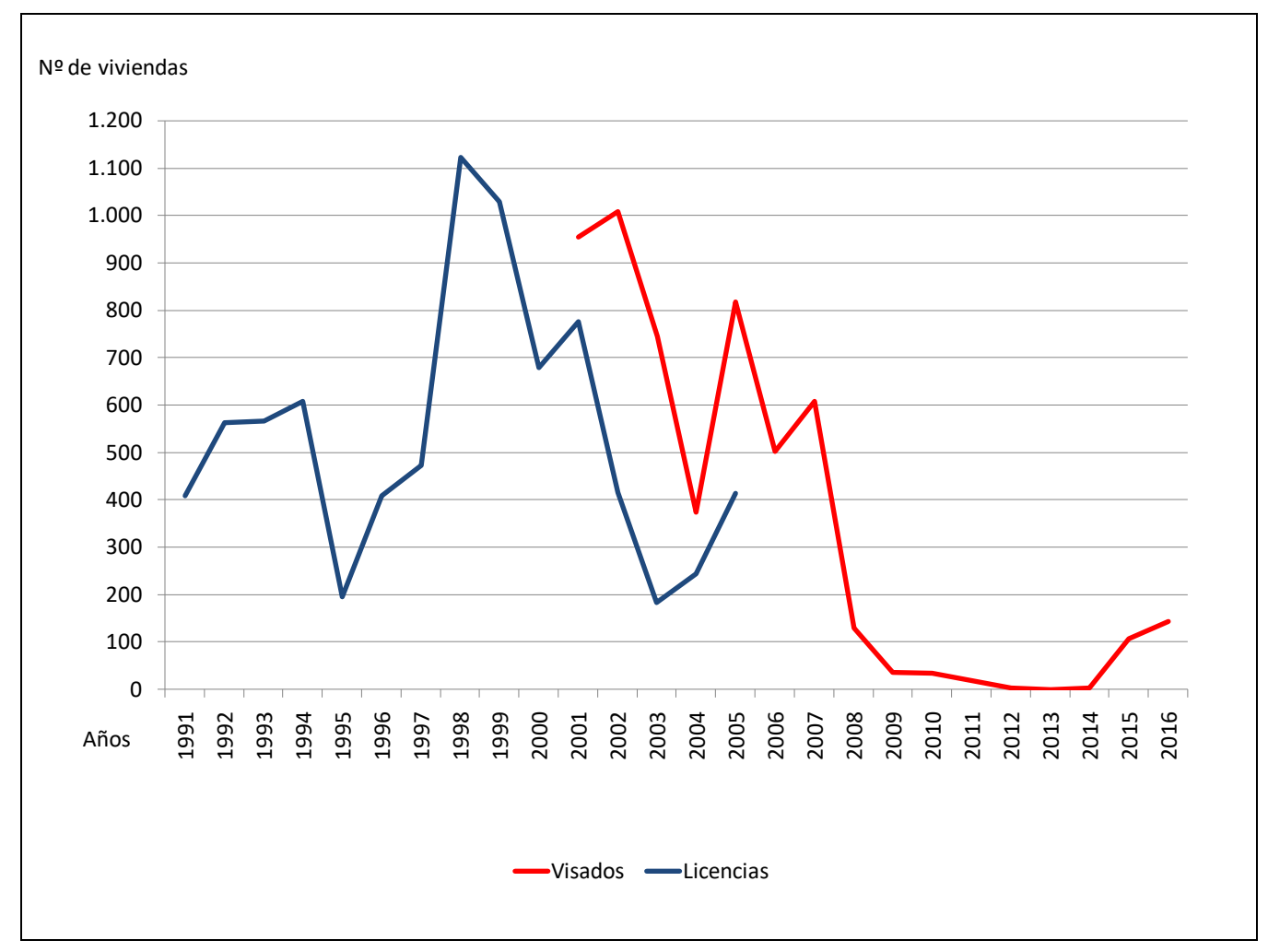

Fuente: elaboración propia a partir de datos de ICANE (licencias)

16 En el mismo Informe se afirma que "No ha sido posible conocer el número de licencias solicitadas y concedidas en el período fiscalizado, ni los expedientes de disciplina urbanística ni las modificaciones del Plan General de Ordenación Urbana" (Tribunal de Cuentas, 2009, p. 11). 
y Colegio Oficial de Aparejadores y Arquitectos Técnicos de Cantabria (COAATCAN) (visados)

Puede aseverarse sin exageración que el municipio de Castro Urdiales es un caso paradigmático de la "crisis del ladrillo" (Burriel, 2014). Especializado en la función residencial dentro de la región metropolitana bilbaína, se desarrolló aquí una actividad edificatoria frenética que ha ido disminuyendo paulatinamente: en el año 2002 se llegaron a visar proyectos para construir 1.007 viviendas mientras que en 2013 no se firmó ni un sólo visado de vivienda de obra nueva; a partir de 2015 la construcción residencial parece que ha empezado a recuperarse con 143 visados de construcción de viviendas en 2016.

Las nuevas construcciones se han extendido hacia el noroeste del casco, en la Ensenada de Urdiales, hasta casi alcanzar el núcleo la pedanía de Allendelagua en el área en que se ha trazado un paseo marítimo que bordea una flamante playa artificial a la que se ha dado el nombre de Ostende. Tras uno y otra se han levantado numerosas edificaciones de bloques que colmatan el espacio comprendido entre la carretera nacional y el antiguo trazado ferroviario, ampliamente desbordados ya hasta llegar a la autovía A-8.

En el sector suroriental ha sucedido lo mismo: hace tiempo que los bloques de viviendas han rebasado el antiguo trazado de las dos líneas ferroviarias e, incluso, han traspasado el límite de la autovía, llegando a la pedanía de Sámano. Es en este sector donde se ha desarrollado lo que podríamos considerar el "nuevo Castro Urdiales", el barrio de Cotolino, que casi enlaza con los barrios de la pedanía de Mioño.

Porque, consumida ya la práctica totalidad del suelo edificable de la entidad principal, la presión inmobiliaria ha llegado a las pedanías, en particular a las más accesibles desde la A-8, Mioño, Santullán, y Sámano, convertidas realmente en barrios de la ciudad, pero con menores dotaciones de equipamientos y servicios.

Uno de los resultados de más de quince años de vértigo constructor es que en Castro Urdiales se ha consolidado un modelo urbanístico especulativo, caótico y con bastantes deficiencias infraestructurales, principalmente en los barrios y pedanías, con una tipología edificatoria monótona y repetitiva (Figura 13).

El proyecto CORINE Land Cover (CoORdination of INformation of the Environment, CLC) y el Sistema de Información sobre Ocupación del Suelo de España (SIOSE) proporcionan información suficientemente expresiva para evaluar la evolución de las formas de ocupación y uso del suelo.

Según los datos de CLC, el suelo artificializado en Castro Urdiales entre 1987 y 2006 ascendió a 237,6 ha $(46,4 \%$ de la superficie artificial en la primera fecha), procedentes en su mayor parte del retroceso de las superficies agrícolas. El proceso tuvo un dinamismo similar en el período 1987- 
2000, en el que el suelo artificial aumentó en 158,7 ha (12,2 ha al año de media), que en el plazo comprendido entre 2000 y 2006, cuando el suelo artificial creció en 78,9 ha (13,1 ha anuales).

Figura 13. Nuevas urbanizaciones en la pedanía de Otañes
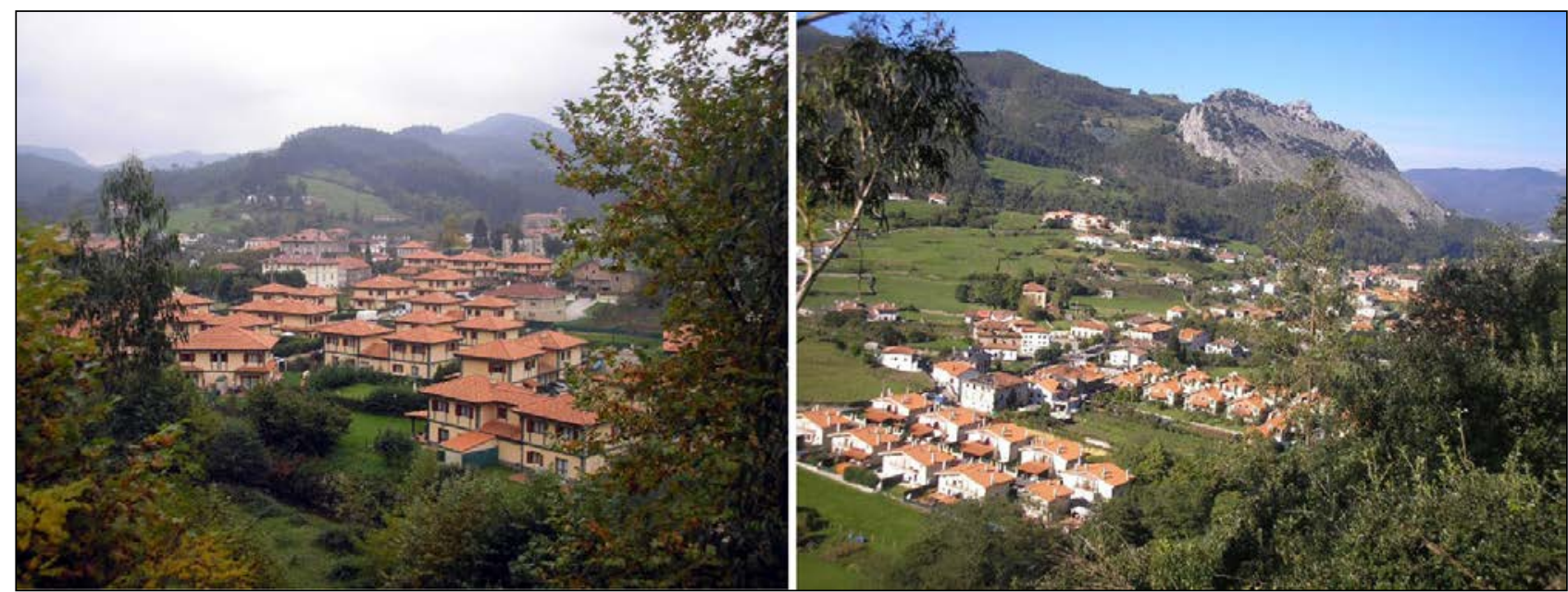

Fuente: Otro Castro es posible (2009)

Los datos aportados por SIOSE, pese a las diferencias metodológicas en su elaboración, permiten completar y matizar los anteriores. En los cuatro años transcurridos entre 2005 y 2009 , como era de esperar por la coincidencia con la crisis inmobiliaria, el proceso de artificialización aparentemente no ha avanzado. No obstante, los aspectos más significativos corresponden a la evolución detallada de cada tipo de cobertura. Así, el suelo cubierto por las edificaciones ha aumentado en sólo cuatro años en 23,2 ha $(7,8 \%)$, en particular el correspondiente a vivienda unifamiliar adosada $(203,4 \%)$ y a vivienda unifamiliar aislada (231,3\%); en menor medida, aunque también con valores importantes, se ha ampliado la superficie cubierta por edificios aislados (59\%).

Tales datos ponen de manifiesto el cambio de tipología edificatoria y, en definitiva, la fijación de un modelo urbano más expansivo y disperso. La dinámica de la distribución de la superficie municipal por categorías de suelo de 2005 a 2009 no deja lugar a dudas sobre el afianzamiento del modelo urbano extensivo: mientras que la superficie de la ciudad consolidada, casco y ensanche, apenas han experimentado cambios significativos, el área de tejido urbano discontinuo ha aumentado en 32,4 ha (96,9\% en relación con la superficie ocupada cuatro años antes).

Entre los cambios recientes cabe también destacar el escaso aumento del suelo industrial (apenas un 4 \%) y la continuación del retroceso de las tierras cultivadas, aunque muy amortiguado.

La presencia física de las actividades productivas industriales tiene mal acomodo en un espacio urbano especializado en funciones terciarias y residenciales. Es esto, junto a la reducción de la importancia de la industria en la base económica castreña, lo que explica el escaso peso del suelo industrial, su alejamiento del núcleo urbano central y la ubicación de las instalaciones industriales en 
las pedanías próximas, en Mioño y, sobre todo, en Sámano. En el término de esta última pedanía se situó el primer, y único hasta ahora, polígono industrial de que dispone Castro Urdiales, el de El Vallegón.

El polígono fue promovido en 1996 por la Dirección General de Industria del Gobierno de Cantabria que encargó la gestión a Suelo Industrial de Cantabria S.L. (SICAN). ${ }^{17}$ Se extiende por una superficie de $142000 \mathrm{~m}^{2}$ ocupada en su mayoría por 50 parcelas pertenecientes, en 2005, a cuarenta y dos empresas con algo más de 500 trabajadores en total..

En septiembre de 2007 la Comisión Regional de Ordenación del Territorio y Urbanismo (CROTU) aprobó inicialmente el Proyecto Singular de Interés Regional (PSIR) ${ }^{18}$ denominado Área Estratégica Industrial de Castro Urdiales ( $1^{a}$ fase). La zona propuesta para desarrollar en la primera fase de la actuación, localizada al este del polígono El Vallegón, al que prácticamente envuelve, ocupa una superficie total de 166.041,95 $\mathrm{m}^{2}$. La actuación ha suscitado bastantes críticas y oposición sobre todo en cuanto a algunos posibles impactos ambientales, paisajísticos y culturales. ${ }^{19} \mathrm{El}$ proyecto salió a concurso en febrero de 2011 y las obras han sido terminadas en la primavera de 2016.

\section{Ordenación del territorio y planeamiento urbanístico}

\subsection{La aplicación del Plan General de Ordenación Urbana de 1997}

El casi inoperante PGOU de 1965 estuvo en vigor treinta y dos años durante los cuales, como se ha expuesto, se construyeron en Castro Urdiales más de diez mil viviendas, el doble de las que tenía la ciudad en la fecha de su aprobación, y se multiplicó varias veces la superficie de suelo urbanizado.

Tras varios intentos fallidos, el 21 de mayo de 1996 se aprobó provisionalmente un nuevo PGOU que obtuvo el visto bueno definitivo de la Comisión Regional de Urbanismo el 23 de diciembre de ese mismo año y fue puesto en vigor a mediados de 1997 (BOC de 6 de junio de 1997).

En dicho Plan se clasificaban 746,5 ha como suelo urbano (de las cuales 678,5 ha como residencial y sólo 68 ha como industrial-terciario), otras 178,4 ha como suelo urbanizable y las restantes 8583,07 ha como suelo no urbanizable.

17 SICAN es una sociedad de capital público que tiene por objeto el desarrollo de suelo industrial, urbanizando espacios industriales y dotándoles de las infraestructuras necesarias.

18 Los Proyectos Singulares de Interés Regional son instrumentos especiales de planeamiento territorial contenidos en la Ley 2/2001, de 25 de junio, de Ordenación Territorial y Régimen Urbanístico del Suelo de Cantabria (Título 1, Sección $3^{a}$, artículos 26 a 29) con el objetivo explícito de proporcionar al Gobierno autonómico una herramienta que le permita garantizar la culminación de aquellos proyectos que tuvieran un alto interés público regional, en el caso de que existiera conflicto con el ayuntamiento o ayuntamientos afectados.

19 El Ayuntamiento presentó en 2008 un contencioso administrativo contra el PSIR alegando que el suelo donde se había de levantar el polígono industrial estaba clasificado en el PGOU vigente como "suelo rústico de especial protección"; dicho contencioso fue retirado en 2011 (EFE, 2011, March 11). 
Por lo que se refiere al suelo urbano, se establecía diferencia entre aquél sobre el que se preveían actuaciones sistemáticas y aquel otro donde las actuaciones a realizar tendrían el carácter de asistemáticas. Las primeras debían llevarse a cabo en un total de 140,5 ha en las que se definieron 107 Unidades de Ejecución (UE) y cuatro Áreas de Planeamiento Diferido (APD).

El suelo urbanizable quedó dividido en programado (SUP) y no programado (SUNP). ${ }^{20}$ El SUP estaba formado por $441169 \mathrm{~m}^{2}$ agrupados en cinco sectores como una única área de reparto. Los $845060 \mathrm{~m}^{2}$ de SUNP eran terrenos en los que, aun siendo aptos para ser urbanizados, no se establecían plazos concretos para su desarrollo urbanístico.

Considerando que cuando se elaboró el PGOU las proyecciones de población eran de 30.800 habitantes permanentes y un máximo estacional de 43700 , el PGOU respetaba los estándares mínimos establecidos. Asimismo, el RDL 1/1992, al que se atuvo el PGOU, fijaba un estándar máximo de 75 viviendas por ha, lo que cumplía rigurosamente el PGOU. No obstante, la Ley de Ordenación Territorial y Régimen Urbanístico del Suelo de Cantabria 2/2001 de 21 de junio (LOTRUSCA, art. 38) determinaba una densidad de 70 viviendas por ha y una edificabilidad de $1 \mathrm{~m}^{2}$ construido por cada $1 \mathrm{~m}^{2}$ de suelo. Estas superiores restricciones explican, sin duda, que el PGOU de Castro Urdiales, al igual que los de muchos otros municipios de Cantabria (Delgado, 2010), no se adaptase posteriormente a dicha normativa regional en los cuatro años de plazo concedidos, lo que implica el incumplimiento de la LOTRUSCA.

Según afirma el referido Informe del Tribunal de Cuentas, no se ha podido determinar el número de modificaciones del PGOU realizadas desde 1997 debido a las "carencias y deficiencias de la información facilitada por el Ayuntamiento" (Tribunal de Cuentas, 2009, p. 40) y porque están incompletos los expedientes disponibles en el Departamento municipal de Urbanismo (Tribunal de Cuentas, 2009, p. 43). Sin embargo, del cotejo realizado por los auditores entre esos expedientes y las actuaciones de la Comisión Regional de Urbanismo, se desprende la realización de, al menos, quince modificaciones, nueve de ellas agrupadas en dos expedientes denegados en su totalidad en 2001 por la propia Comisión al entender que "debían englobarse en una revisión general del planeamiento municipal" (Tribunal de Cuentas, 2009, p. 41). Más tarde, y como consecuencia de la interposición de varios recursos, se aprobó parte del contenido de los dos expedientes aludidos como modificaciones puntuales.

Como es habitual, la mayoría de las modificaciones del PGOU que se han podido constatar han ido siempre en la dirección de ampliar el suelo urbanizable para uso residencial mediante reclasificaciones y recalificaciones. En otras ocasiones se ha procedido a alterar la edificabilidad a través de convenios urbanísticos firmados con los propietarios de los terrenos.

20 El RDL 5/1996 de 7 de junio eliminó la distinción entre suelo urbanizable programado y no programado. 
En resumen, y según la información que pudo recabar la auditoría del Tribunal de Cuentas, en 2007 se había ampliado la superficie del suelo urbano y urbanizable, respecto a las previsiones del Plan, en 295148 m² $^{2}$ 10,7 \% más, a través de diferentes modificaciones (Tribunal de Cuentas, 2009, p. 47).

Además de las variaciones, se han producido bastantes irregularidades en la aplicación del PGOU; entre ellas cabe destacar por sus consecuencias las referidas a la cesión de aprovechamientos urbanísticos.

En el PGOU figuraba la cesión obligatoria del 10\% del aprovechamiento urbanístico en los sectores de SUP y en las áreas de planeamiento diferido de suelo urbano. Aunque no se explicitaba, se aplicaba también el $10 \%$ a las Unidades de Ejecución de suelo urbano, si bien en la Memoria del PGOU se establecía la cesión del $15 \%$ en dichas unidades de acuerdo con lo dispuesto en el RDL 1/1992. Por otra parte, el Ayuntamiento no requirió la cesión del aprovechamiento urbanístico en diez de las sesenta Unidades de Ejecución iniciadas y en otras nueve, en las que se había convenido la sustitución del aprovechamiento por su equivalente económico, no se realizaron las gestiones necesarias para el cobro de su importe (Tribunal de Cuentas, 2009, p. 108).

En otros casos no se cumplió la reserva de suelo para dotaciones mínimas de espacios y equipamientos públicos. ${ }^{21}$ A veces, en los convenios de permuta se infravaloraron los terrenos aportados por el Ayuntamiento y se sobrevaloraron los recibidos con un importante perjuicio financiero para el Ayuntamiento (Tribunal de Cuentas, 2009, p. 109). Han sido relativamente frecuentes también las alteraciones de la tipología de edificación, sustituyendo la de unifamiliar por colectiva y aumentando la edificabilidad.

Las irregularidades y deficiencias de tramitación y ejecución del planeamiento se acompañan de otras relativas a la gestión urbanística propiamente dicha. Como denuncia el referido Informe, ha sido deficiente la gestión de la documentación y nunca se realizó forma alguna de inspección urbanística, por lo que las pocas actuaciones disciplinarias tramitadas han tenido siempre su origen en denuncias de terceros (Tribunal de Cuentas, 2009, p. 109).

\subsection{La fallida elaboración de un nuevo Plan General de Ordenación Urbana}

En 2004 se iniciaron los trámites para la revisión del PGOU con la convocatoria de un concurso público para proceder a la contratación de un equipo redactor. A dicho certamen sólo se presentó una propuesta, la de una UTE formada por dos empresas de una de las cuales era socio uno de

21 Las carencias en equipamientos y servicios se han atribuido en muchas ocasiones a la deficiente gestión y aplicación del PGOU de 1997: "el actual Plan General, aprobado en 1996, ha dejado un déficit de equipamientos públicos [...] En estos momentos no disponemos de suelos dotacionales aptos para centros educativos, deportivos, culturales y asistenciales (colegios, polideportivos, hospital. etcétera)" (EFE, 2010, October 2). 
los empresarios de la construcción más activos de la ciudad. ${ }^{22}$ El proyecto se orientó inmediatamente hacia la redacción de un nuevo PGOU que se pretendía presentar pocos meses después, en enero de 2008, y que, en teoría, no afectaría al núcleo principal del municipio sino a las pedanías y haría hincapié en la disponibilidad de terrenos para equipamientos. ${ }^{23}$

Un documento inicial se hizo público en junio de 2009 y en agosto se inició el expediente de evaluación ambiental con la presentación de la Memoria Resumen del PGOU a fin de proceder a su tramitación; más de un año después, en septiembre de 2010, se proporcionó a los portavoces de los Grupos Municipales un documento de avance del PGOU. La consulta del documento preliminar completo (Memoria Resumen, Anexos y seis planos) se hizo accesible en la página Web del propio Ayuntamiento.

A sabiendas de que este documento dista mucho de lo que podría ser el documento final, parece conveniente hacer un análisis somero de su contenido para aproximarse de forma provisional a la orientación que seguiría el futuro Plan en caso de llegar a elaborarse a partir de ese avance.

Del documento publicado destaca, en primer lugar, su factura, que parece delatar cierto apresuramiento en la elaboración, tal vez con la intención de cubrir el expediente de la presentación de algún documento a punto de finalizar el plazo otorgado en la contrata al equipo redactor. Los defectos formales en la redacción de la Memoria y Anexos y la falta de coincidencia de algunas cifras, cuando se aportan datos numéricos, fundamentan la opinión formada a partir de la lectura de la parte expositiva de la Memoria, que podría calificarse, además, de poco rigurosa.

Apenas se dedica una página a la exposición de la normativa aplicable al desarrollo del Plan, tanto de escala estatal como autonómica, sin precisar en absoluto los mecanismos de adaptación a tales normas. Por lo que se refiere a la incidencia del POL, se considera que constituye un condicionante que limita las posibilidades de crecimiento urbanístico (Ayuntamiento de Castro Urdiales, 2010, p. 22). El conocimiento del modelo territorial existente se apoya únicamente en un brevísimo capítulo de "diagnóstico territorial" y otro, de menor extensión aún, de "consideraciones previas al modelo territorial propuesto".

22 El contrato se firmó el 4 de mayo de 2007 con la UTE San Andrés, Estudio de Arquitectura, Ingeniería y Urbanismo S.L. y Marcial Echenique y Cía, por un total de 349.000 euros. El equipo disponía de un plazo de ejecución del trabajo de veintidós meses bajo la observación de una Comisión municipal de Seguimiento que no se reunió nunca. En un auto dictado por el juzgado $n^{\circ} 2$ de Castro Urdiales para concluir la instrucción de un caso en el que se investigaban las irregularidades en materia de contratación que había puesto de manifiesto el Tribunal de Cuentas, se afirmaba que el Ayuntamiento contrató "a dedo" a la empresa Dirsur para que hiciera un texto refundido de su plan de urbanismo con el objetivo de "maquillar las ilegalidades que se estaban cometiendo" (Verano, 2011, February 2).

23 Se pretendía incluir en el Plan el PSIR del Polígono de El Vallegón y la posibilidad de contemplar nuevas comunicaciones con Vizcaya: un autobús lanzadera desde Castro hasta la estación de FEVE de Muskiz, así como la prolongación del ferrocarril de vía estrecha en sentido Muskiz-Castro Urdiales). 
El análisis de los caracteres de la población, que debería ser clave para evaluar las necesidades residenciales y dotacionales, es muy superficial. No se ha hecho un estudio a fondo de la extraordinaria evolución previa del parque inmobiliario, ni de las necesidades y la demanda de vivienda. En ambos aspectos el estudio se reduce al manejo trivial de unos pocos datos básicos del Censo de Población y Vivienda de 2001, que habían quedado ampliamente superados en las fechas de redacción del documento. Se hace, así, una injustificada proyección del crecimiento de la población y de la vivienda para el horizonte de 2025: 65863 habitantes censados y 47906 estacionales y un incremento del número de viviendas hasta llegar a 40406.

La Memoria casi no aborda el examen de las realizaciones y el grado de desarrollo (aciertos, deficiencias y carencias) del Plan de 1997, más allá de alegar de forma sucinta que el principal motivo de la revisión es el hecho de que buena parte de sus objetivos no han podido ser desarrollados, sin especificar cuáles ni por qué. El aspecto más revelador del dictamen sobre las realizaciones del Plan vigente es el reconocimiento de la notoria insuficiencia dotacional que padece el municipio (Ayuntamiento de Castro Urdiales, 2010, pp. 20-21).

Por tal motivo, se pone el acento en la potenciación de los equipamientos, infraestructuras y servicios generales, en particular en las Juntas/Pedanías, de forma que resulten más adecuados para la población y mejor localizados para estructurar la trama urbana, aunque no se dice cómo ni se cuantifican las previsiones. Algo que resultaría imprescindible más aún cuando un conjunto de objetivos se orienta al crecimiento de la población empadronada (Ayuntamiento de Castro Urdiales, 2010, p. 24), pese a que el modelo poblacional esbozado en teoría se propone "contener el crecimiento de la población" (Ayuntamiento de Castro Urdiales, 2010, 25-27).

Un año después de haberse hecho público el borrador de avance del PGOU, ningún grupo político había presentado alegaciones por lo que el gobierno municipal, a propuesta del partido ecologista CastroVerde, acordó agilizar su revisión y elaborar un Plan Estratégico para el municipio con el horizonte 2022. Todavía en 2012 se reiteró la intención de retomar el trabajo a fin de presentar en breve plazo un avance de PGOU sustituyendo las propuestas de crecimiento por las de reorganización urbanística. El proceso volvió a paralizarse tras las reclamaciones del equipo redactor de un importante adelanto financiero para continuar con la reelaboración, casi al mismo tiempo que la empresa adjudicataria iniciaba los trámites de liquidación, por lo que se consideró la posibilidad de contratar a otra empresa para hacer la revisión del Proyecto. Tales propuestas han quedado abandonadas o, al menos, paralizadas, de forma que Castro Urdiales sigue a día de hoy sin un planeamiento urbanístico y/o estratégico adecuado para reparar los efectos de la burbuja inmobiliaria (Gaja, 2015) y para proyectar el futuro socioeconómico y urbanístico de la ciudad. 


\subsection{Conflictividad y judicialización de la actividad urbanística}

En febrero de 2009 un periódico de tirada nacional publicaba un artículo titulado "Un Ayuntamiento fuera de control. Un juez investiga una decena de delitos en Castro Urdiales e imputa al alcalde" (Junquera, 2009, February 23). En él se hacía referencia a "Viviendas construidas sin licencia, sin agua o sin luz [...] Urbanizaciones que no aparecen en los mapas, es decir, en los planes de ordenación urbana [...] una pequeña muestra de las irregularidades que un juez [...] ha detectado en Castro Urdiales (Cantabria)". La información contenida en dicho artículo guardaba relación con hechos acaecidos durante bastantes años y que cabe considerar como el ingreso definitivo del desarrollo inmobiliario y urbanístico castreño en el ámbito judicial.

En el origen de la actuación judicial se encuentra el citado Informe de Fiscalización del Tribunal de Cuentas a través del cual se descubrieron irregularidades e indicios de delito en más de treinta ejecuciones urbanísticas: contra la ordenación del territorio, contra el patrimonio histórico, de prevaricación, cohecho, tráfico de influencias, malversación de fondos públicos, falsedad documental, blanqueo de capitales y estafa. Un acervo delictivo muy similar al de otros muchos casos de corrupción urbanística ocurridos durante la fase de "burbuja inmobiliaria" también en otros territorios.

El magistrado había ordenado la detención de dieciocho personas pertenecientes a todos los partidos políiticos, entre las que se encontraban el alcalde presente, el alcalde anterior, cuatro ediles de la corporación municipal del momento y seis de la precedente, una docena de técnicos y funcionarios y siete promotores inmobiliarios. Al avanzar la investigación, el fiscal consideró que lo sucedido se enmarcaba en el "desarrollo urbanístico explosivo" vivido en Castro Urdiales en los últimos años caracterizado por la "absoluta falta de control y rigor" (Cerro, 2010, February 4). En resumen, en 2011, 630 viviendas y 2 edificios educativos se encontraban bajo procedimientos jurídicos abiertos al tratarse de edificaciones construidas sin licencia, sobre cauces de agua, en suelo rústico o público, etc. (Portell, 2011, January 10). Ese mismo año, el alcalde, tres concejales y otros administradores y políticos fueron condenados a siete años y medio de inhabilitación para desempeño de cargo público por la adjudicación irregular de obras.

Uno de los primeros efectos de estos procesos fue la paralización de la actividad constructora y urbanística, hasta el punto de requerir la iniciativa del Gobierno autonómico para buscar soluciones a una situación insostenible y prolongada durante varios años. Además de los graves perjuicios sufridos por los presupuestos municipales derivados de las sentencias que obligaban a pagar indemnizaciones a las promotoras inmobiliarias por la mala gestión realizada por el Ayuntamiento.

Las reacciones de algunos de los imputados no se hicieron esperar $y$, entre otras, consistieron en el intento de apartar de la investigación al juez instructor de las causas, alegando que se estaba 
paralizando el normal funcionamiento del Ayuntamiento, en particular en lo que a actuaciones urbanísticas se refiere.

Asimismo, una inmobiliaria presentó una querella criminal contra el magistrado por presunto delito de prevaricación que, aunque archivada provisionalmente en principio por el Tribunal Superior de Justicia de Cantabria, fue admitida después por el mismo tribunal (n.a., 2014, April 25). Finalmente, el juez demandado se trasladó a un juzgado de Santander, tras serle denegada una prórroga para cerrar los casos de corrupción que se encontraban en fase de instrucción, y poco después la Sala Penal del Tribunal Supremo revocó el sobreseimiento y archivo de la causa seguida contra él por delito de descubrimiento y revelación de secretos. Suspendido provisionalmente de funciones por la Comisión Permanente del Consejo General del Poder Judicial y condenado a un año y tres meses de prisión y a tres años de inhabilitación, por último el juez, tras presentar un recurso de casación, resultó absuelto por el Tribunal Supremo, que anuló la sentencia condenatoria anterior (EFE, 2016, July 4).

El largo y enrevesado proceso, que he intentado sintetizar al máximo, aun a sabiendas de que podría dar lugar a la escritura de un extenso tratado sobre irregularidades y conflictividad urbanísticas extrapolable a otros lugares, se desarrolla en torno a varios casos, que pueden ser considerados paradigmáticos de lo ocurrido aquí y en muchos otros sitios, además de los que dieron lugar a las actuaciones judiciales expuestas antes.

Uno de los sectores que ha resultado más conflictivo es el del SUP-4 en el área de Santa Catalina, que tenía asignada en el PGOU la función prioritaria de ser espacio deportivo, cultural y de ocio del municipio y, en conjunto, solventar parte de las carencias dotacionales que padecía. ${ }^{24}$

El caso de La Loma (SUNP-3 y SUNP-12) es otro de los asuntos urbanísticos en que se centró la instrucción judicial desde que comenzó la investigación. ${ }^{25} \mathrm{Al}$ margen de otras consecuencias, el Ayuntamiento sufrió un importante menoscabo en sus ingresos, calculado en 9,3 millones de euros por falta de aprovechamientos, cesiones obligatorias y tasas impagadas.

La problemática urbanística que ha vivido Castro Urdiales en los últimos años ha tenido la facultad de suscitar algunas reacciones de una parte de la ciudadanía castreña que, incluso, trata de

24 Se calcula que el Ayuntamiento perdió más de 1,3 millones de euros en el desarrollo urbanístico de este sector (Verano, 2012, January 18). Al final la causa fue sobreseída y poco después fueron declaradas legales las viviendas edificadas.

25 Todavía en 2016 el Ayuntamiento publicó un edicto informativo advirtiendo sobre los riesgos inherentes a la adquisición de viviendas ubicadas en áreas de Suelo Urbanizable No Programado de la Loma ya que carecen de licencias de primera ocupación "debido a los problemas urbanísticos en los que llevan inmersos desde casi un década y que han implicado varios procesos judiciales" (Chato, 2016, March 14). 
recuperar, como antecedentes, los movimientos ciudadanos que tuvieron lugar contra el Proyecto Castro Novo a finales de los años setenta del siglo XX. ${ }^{26}$

\section{Figura 14. Vistas panorámicas de Castro Urdiales desde El Cueto hacia 1930 y en la actualidad}

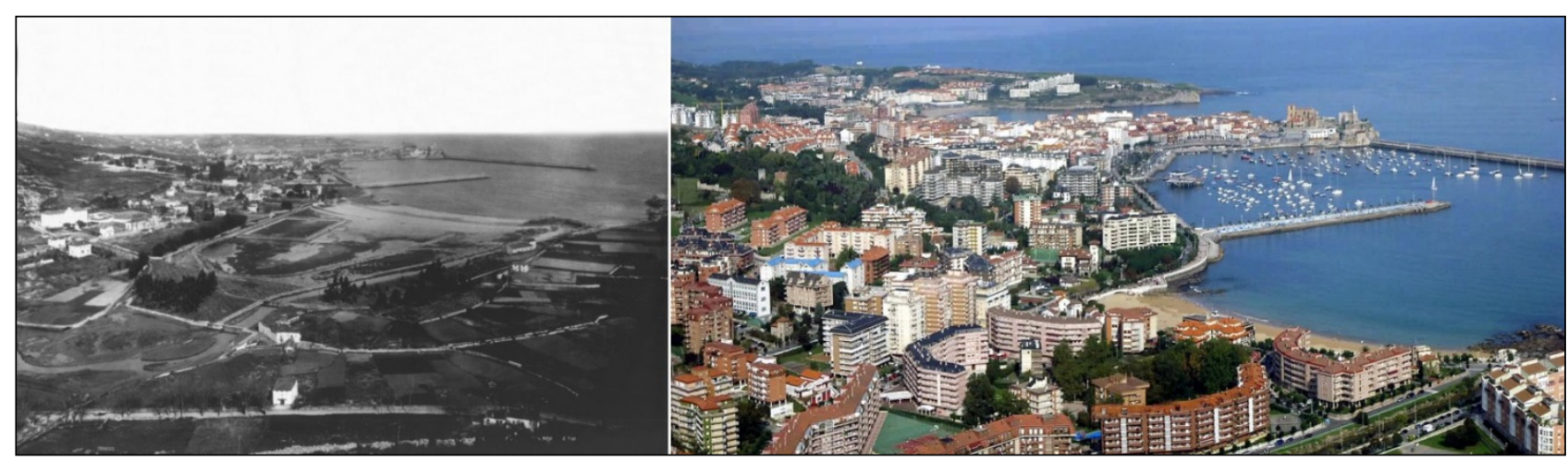

Fuente: CDIS (s.f., ca. 1930) y Ayuntamiento de Castro Urdiales (2013)

\section{Reflexiones conclusivas}

Castro Urdiales ejemplifica una de las formas de ampliación de las áreas metropolitanas a través de la integración funcional de núcleos urbanos preexistentes. Integración que, en esta ocasión, ha sido facilitada por unas relaciones territoriales y socioeconómicas previas, pero cuyo factor estimulante principal ha sido, como en la mayoría de los casos, la mejora de la accesibilidad desde el núcleo central de la aglomeración urbana a través de la construcción de una vía de circulación rápida, la A-8, puesta en pleno funcionamiento a principios de los años noventa del siglo XX.

El análisis de este caso pone de manifiesto, igualmente, como las formas de articulación y las funciones que cada parte del territorio metropolitano desempeñan para el conjunto de la región urbana son diferentes y pueden ir modificándose al compás del cambio de las demandas de la aglomeración y, en especial, de las de su entidad principal. Así, los primeros pasos del proceso de articulación de la ciudad castreña en el área vizcaína consistieron en la adopción de su función como una zona complementaria de explotación minera y un espacio de ocio y esparcimiento al servicio de la burguesía industrial. Inicialmente para el veraneo tradicional de las clases altas y, más tarde, para el disfrute estival de grupos cada vez más amplios de población, clases medias sobre todo, a partir de los años sesenta y setenta del siglo XX. Esta función conllevó el comienzo de la terciarización de la base económica urbana y el crecimiento y especialización de la ciudad en la residencia secundaria y la vivienda vacacional.

26 En 2011 se fundó un nuevo partido, "CastroVerde, Alternativa Verde de Castro Urdiales", que obtuvo la mayoría de los votos en las elecciones municipales de 2015 y que gobierna el Ayuntamiento castreño desde esa fecha. 
El incremento poblacional del "Gran Bilbao" generó nuevas necesidades e impuso un cambio en la funcionalidad de Castro Urdiales para atender a la descongestión residencial de Bilbao. Se añade así a su función anterior la de espacio residencial permanente para un creciente volumen de población, procedente del área metropolitana, que encuentra aquí vivienda más barata en un entorno de mayor calidad ambiental y sosiego social. El detonante final de la mutación funcional fue la apertura de la autovía, que situó la localidad cántabra a menos de media hora del centro de Bilbao.

Las nuevas funciones fueron muy bien aceptadas por las instituciones de administración local, que advertían como crecían rápidamente los recursos financieros procedentes del aumento de la población, aunque no toda se censara oficialmente, y del auge de la actividad económica, en particular la hostelería, el comercio y, sobre todo, la construcción residencial.

Como núcleo perimetropolitano situado en una Comunidad Autónoma distinta de aquélla en la que se ubica el núcleo central de la aglomeración, Castro Urdiales acredita, además, la escasa virtualidad de los límites político-administrativos como obstaculizadores de la ampliación funcional de las áreas metropolitanas. Lo que no significa que este tipo de lindes carezcan de efectos añadidos a la problemática y los conflictos asociados a todos los procesos acelerados de urbanización y metropolitanización.

El papel asignado a Castro Urdiales, y asumido por la ciudad, en la aglomeración urbana bilbaína ha coadyuvado al retroceso de las actividades productivas en la base económica del municipio en su conjunto, en particular las actividades primarias, que habían sido el soporte de la actividad industrial hasta mediados del siglo XX. El declive agropecuario, pesquero e industrial ha sido proseguido por un rápido proceso de terciarización en la segunda mitad de esa centuria, que ha reducido la base económica a las actividades de servicios, turismo y comercio, y a la construcción. De forma que la economía urbana va quedando limitada y subordinada a las actividades vinculadas a la función residencial: los servicios turísticos y de ocio en general, el comercio y los servicios públicos para atender a una parte de la población residente y del entorno comarcal. Unas actividades que están sujetas a grandes limitaciones porque buena parte del consumo de bienes y servicios se realiza en la cercana ciudad de Bilbao con una oferta mucho más amplia y diversificada.

Otro de los efectos más llamativos del proceso es la eclosión de una desaforada actividad edificatoria desde finales del siglo XX, que casi ha triplicado el volumen del parque inmobiliario en poco más de veinte años, modificado los usos del suelo y ampliado notablemente las superficies artificializadas, lo que ha redundado en una importante transformación estructural, morfológica y paisajística del territorio. 
La ampliación del espacio urbano y la modificación de la morfología han venido impuestas, en primer lugar, por la demanda de espacios para la construcción de edificios a fin de albergar a la población residente estacional. El proceso ha continuado con la urbanización de nuevas áreas para alojar a población residente permanente desde finales del siglo pasado hasta la actualidad. En ambas ocasiones, el factor promotor ha sido el aumento de la accesibilidad, primero a través de la construcción de carreteras y vías férreas y, un siglo más tarde, a partir del trazado de la autovía.

El frenesí constructor no es ajeno a la ineficacia de los instrumentos de planeamiento, ignorados a veces y alterados casi siempre, cuando no elaborados con el propósito de propiciar el desarrollo inmobiliario desmedido y legitimar las irregularidades cometidas previamente. Ambos aspectos no están irremisiblemente vinculados, pero sí coinciden con mucha frecuencia. La mala gestión y aplicación del planeamiento suele conducir a una exacerbada conflictividad urbanística y a la judicialización de esta problemática, como ha ocurrido en Castro Urdiales donde han acarreado la paralización temporal de las actividades urbanísticas y la quiebra de las finanzas municipales. Cabría sospechar, incluso, que ha originado una cierta incapacidad, o resistencia, a elaborar instrumentos de ordenación y planeamiento eficaces.

La dinamización demográfica es otro de los resultados producidos por la integración de Castro Urdiales en el área metropolitana. Aquí ha tenido lugar un precipitado incremento de la población residente censada y, sobre todo, de la población residente habitual no censada, a partir de dos factores demográficos estrechamente relacionados: la inmigración, en particular la vinculada a la movilidad residencial intrametropolitana, de grupos de población en las edades de mayor capacidad productiva y reproductiva y el aumento del saldo vegetativo a causa del alza coyuntural de la natalidad.

Son circunstancias positivas a primera vista pero que, combinadas con otros factores, se traducen en una significativa problemática, el aumento de las deficiencias en la dotación de algunos equipamientos y servicios esenciales, agravada por la gran diferencia existente entre la población fiscalmente contribuyente y la población real, consumidora de equipamientos y servicios cuyo mantenimiento sólo sufraga parcialmente. El problema se muestra en la merma de los ingresos municipales y los déficits para satisfacer el coste de los servicios demandados y consumidos por todos los residentes. Aunque ésta no sea la única causa de las carencias en la dotación de equipamientos sanitarios y educativos, de las deficiencias en el abastecimiento de agua, o de los problemas de accesibilidad provocados por la congestión de la autovía y los atascos cotidianos en las horas-punta previas al inicio y la finalización de la jornada laboral, de los períodos vacacionales y fines de semana.

Declaración responsable: La autora declara que no existe ningún conflicto de interés. 


\section{Bibliografía}

Arroyo, M. (2001). La contraurbanización: un debate metodológico y conceptual sobre la dinámica de las áreas metropolitanas. Scripta Nova, 97. Retrieved from http://www.ub.edu/geocrit/sn$\underline{\text { 97.htm }}$

Arroyo, M. (2002). El mercado de trabajo y la reestructuración de las áreas metropolitanas. Scripta Nova, 119. Retrieved from http://www.ub.edu/geocrit/sn/sn119-60.htm

Ascher, F. (1995). Métapolis, ou l'avenir des villes. París: Odile Jacob.

Ascher, F. (2004). Los nuevos principios del urbanismo. Madrid: Alianza Editorial.

Ascher, F. (2009). L'âge des metápoles. La Tour d'Aigues: Éditions de l'Aube.

Ayuntamiento de Castro Urdiales (2010). Proyecto de PGOU (Unpublished).

Beascoechea, J. Ma. (2017). De la estancia de baños al veraneo de clase media. El cambio de modelo urbano en Plentzia, Bizkaia (1890-1975). Scripta Nova, 568. Retrieved from http://revistes.ub.edu/index.php/ScriptaNova/article/view/19238/21654

Bell, D., \& Jayne, M. (Eds.) (2006). Small cities: Urban experience beyond the metropolis. London: Routledge.

Berger, F. (2005). Développement de l'emploi transfrontalier et portrait sociodé-mographique des frontaliers. Population \& Emploi, 8. Retrieved from http://www.statistiques.public.lu/cataloguepublications/population-emploi-CEPS/2005/PDF-Population-et-Emploi-8-2005.pdf

Berry, B. J. L. (1976). Urbanization and counterurbanization. Beverly Hills: Sage Publications.

Borja, J., \& Castells, M. (1997). Local y Global. La gestión de las ciudades en la era de la información. Madrid: Taurus.

Burriel, E. (2008). La "década prodigiosa" del urbanismo español (1997-2006). Scripta Nova, 270. Retrieved from http://www.ub.edu/geocrit/sn/sn-270/sn-270-64.htm

Burriel, E. (2014). El estallido de la burbuja inmobiliaria y sus efectos sobre el territorio. In J. M. Albertos, \& J. L. Sánchez (Eds.), Geografía de la crisis económica en España (pp. 101-140). Valencia: Publicaciones de la Universitat de València.

Capel, H. (2003). La cosmópolis y la ciudad. Barcelona: Ediciones del Serbal.

Capel, H. (2009). Las pequeñas ciudades en la urbanización generalizada y ante la crisis global. Investigaciones Geográficas, 70, 7-32.

Capel, H. (2010). Urbanización Generalizada, derecho a la ciudad y derecho para la ciudad. Scripta Nova, 331. Retrieved from http://www.ub.edu/geocrit/sn/sn-331/sn-331-7.htm 
Cerro, M. (2010, February 24). La Fiscalía pide 3 años de cárcel para el ex secretario César Saiz. El Diario Montañés. Retrieved

from http://www.eldiariomontanes.es/v/20100224/region/region-oriental/fiscalia-pide-anoscarcel-20100224.html

Chato, P. (2016, March 14). Castro Urdiales advierte de la "ilegalidad" de ocupar las viviendas de La Loma. El Diario Montañés. Retrieved from http://www.eldiariomontanes.es/castrooriental/201603/14/castro-urdiales-advierte-ilegalidad-20160314135409.html

Corboz, A. (1995). L'ipercittà. Urbanistica, 103.

Cuadrado, S. (2016). La metropolización del territorio en el cambio de siglo: dispersión metropolitana, urbanización del medio rural y transformación de los espacios turísticos en la Europa mediterránea. Biblio3W, 1154. Retrieved from http://www.ub.edu/geocrit/b3w-1154.pdf

Delgado, C. (2008). Vivienda secundaria y turismo residencial como agentes de urbanización y segregación territorial en Cantabria. Scripta Nova, 261. Retrieved from http://www.ub.edu/geocrit/sn/sn-269.htm

Delgado, C. (2010). La ordenación territorial en Cantabria: Normas, planes, proyectos y realidades. Cuadernos Geográficos de la Universidad de Granada, 47, 453-491.

Delgado, C. (2011). Castro Urdiales (Cantabria), de "villa marinera" a ciudad de servicios. La transformación urbanística de una "ciudad de frontera". Ería, 86, 237-270.

Delgado, C. (2011). Infraestructuras de transporte y espacio urbano: el caso modélico de Castro Urdiales (Cantabria). Revista TST, 20, 106-137.

Delgado, C. (2015). Estructura y forma de la ciudad a través de la cartografía histórica. Castro Urdiales, Cantabria (1800-1960). Investigaciones Geográficas, 63, 17-32. doi: http://dx.doi.org/10.14198//NGEO2015.63.02

Dematteis, G. (1991). La scomposizione metropolitana. Quaderni di Lotus, 15, 26-33.

EFE, Agencia. (2010, October 2). La aprobación inicial del PGOU no se producirá en lo que queda de legislatura. El Diario Montañés. Retrieved from http://www.eldiariomontanes.es/v/20101002/region/region-oriental/aprobacion-inicialpgou-producira-20101002.html

EFE, Agencia (2011, March 11). El Consistorio castreño retira el recurso contra el PSIR de Vallegón. El Diario Montañés. Retrieved from http://www.eldiariomontanes.es/v/20110311/region/regionoriental/consistorio-castreno-retira-recurso-20110311.html

EFE, Agencia (2011, June 1). El sindicato STEC califica de "explosiva" la situación de escolarización en Castro.

El Diario Montañés.

Retrieved 
from http://www.eldiariomontanes.es/v/20110601/region/region-oriental/sindicato-stec-calificaexplosiva-20110601.html

EFE, Agencia (2012, February 3). Cantabria pide al Gobierno Vasco que atienda de nuevo a pacientes de Castro. El Diario Montañés. Retrieved from http://www.eldiariomontanes.es/20120203/local/cantabria-general/buruaga-sanidad-paisvasco-201202031529.html

EFE, Agencia (2016, July 4). El Supremo absuelve al juez Acayro y anula la condena de cárcel e inhabilitación. El Diario Montañés. Retrieved from hitp://www.eldiariomontanes.es/castrooriental/201607/04/supremo-absuelve-juez-acayro-20160704154223.html

Escudero, L. J. (2000). La industria transformadora de la pesca. Implantación, desarrollo y afianzamiento del sector en el País Vasco: 1841-1905. Itsas Memoria, 3, 289-327.

Feria, J. Ma. (1999). Nuevas periferias urbanas y planificación pública. In La ciudad: tamaño y crecimiento (pp. 309-316). Antequera (Málaga): Asociación de Geógrafos Españoles.

Feria, J. M. (2004). Problemas de definición de las áreas metropolitanas en España. Boletín de la Asociación de Geógrafos Españoles, 38, 85-99.

Feria, J. Ma. (2006). Los procesos metropolitanos como expresión relevante de la nueva realidad territorial. In J. Ma. Feria (Coord.), Los procesos metropolitanos: materiales para una aproximación inicial (pp. 11-15). Sevilla, Centro de Estudios Andaluces.

Feria, J. Mª. (2010). La movilidad residencial y los procesos de urbanización metropolitanos en España. In , J. Mª. Feria, \& J. M. Albertos (Coords.), La ciudad metropolitana en España: procesos urbanos en los inicios del siglo XXI (pp. 23-47). Cizur Menor (Navarra): Civitas Thomson Reuters.

Feria, J. M. (2013). Hacia una taxonomía de las áreas metropolitanas españolas. Boletín de la Asociación de Geógrafos Españoles, 63, 409-506.

Feria, J. M., \& Andujar, A. (2015). Movilidad residencial metropolitana y crisis inmobiliaria. Anales de Geografía, 35(1), 13-40. doi: hitp://dx.doi.org/10.5209/rev_AGUC.2015.v35.n1.48962

Font, A. (2007). Morfologías metropolitanas contemporáneas de baja densidad. In F. Indovina (Coord.), La ciudad de baja densidad. Lógicas, gestión y contención (pp. 97-107). Barcelona: Diputació de Barcelona.

Gaja, F. (2004). Evidencias e hipótesis: sobre la forma de la ciudad informacional. Ciudad y Territorio. Estudios Territoriales, XXXVI(141-142), 507-516.

Gaja, F. (2015). Reparar los impactos de la burbuja constructora. Scripta Nova, 517. Retrieved from hitp://revistes.ub.edu/index.php/ScriptaNova/article/view/15121 
Gerber, P., Klein, O., \& Carpentier, S. (2012). Movilidad local y periurbanización transfronteriza. Frontera Norte, 24(47), 63-88.

Gil-Alonso, F., \& Bayona-Carrasco, J. (2012). La dinámica urbana en España: evolución y tipología. Papeles de Geografía, 55-56, 95-108.

Gude, E. (2011, October 10). La línea de autobús que une Castro y Bilbao no da abasto. El Diario Montañés. Retrieved from http://www.eldiariomontanes.es/v/20111013/region/regionoriental/linea-autobus-castro-bilbao-20111013.html

Hortas-Rico, M. (2014). Urban Sprawl and municipal budgets in Spain: a dynamic panel data analysis. Papers in Regional Science, 93(4), 843-864. doi: http://dx.doi.org/10.1111/pirs. 12022

Indovina, F. (2003). La "metropolizzazione del territorio". Nuove gerarchie territoriali. Economia e Società Regionale, 21(3-4), 46-85.

Indovina, F. (2009). Dalla città diffusa al arcipelago metropolitano. Milan: Franco Angeli.

Indovina, F. (2013). Verso una nuova dimensione metropolitana. Treballs de la Societat Catalana de Geografia, 75, 149-164. doi: http://dx.doi.org/10.2436/20.3002.01.26

Junquera, N. (2009, February 23). Un Ayuntamiento fuera de control. El País. Retrieved from https://elpais.com/diario/2009/02/23/espana/1235343614_850215.html

Marmolejo, C., Masip, J., \& Aguirre, C. (2013). Policentrismo en el sistema urbano español: un análisis para 7 áreas metropolitanas. Ciudad y Territorio. Estudios Territoriales, 176, 281-300.

Marmolejo, C., \& Tornés, M. (2015). ¿'Reduce el policentrismo la movilidad laboral? Un análisis para las siete grandes áreas metropolitanas en España. Scripta Nova, 500. Retrieved from http://revistes.ub.edu/index.php/ScriptaNova/article/view/15095

Marmolejo, C., Ruiz, N., \& Tornés, M. (2015). ¿Cuán policéntricas son nuestras ciudades? Ciudad y Territorio. Estudios Territoriales, XLVII(186), 679-700.

Martínez, P. M. (2016). La metropolización afectada por la globalización: reflexión epistemológica sobre la nueva revolución urbana. Cuadernos de Geografía, 25(2), 77-105. doi: http://dx.doi.org/10.15446/rcdg.v25n2.56907

Mattos, C. de (2001). Metropolización y suburbanización. EURE, 27(80).

Mattos, C. de. (2010). Globalización y metamorfosis metropolitana en América Latina. De la ciudad a lo urbano generalizado. Revista de Geografía Norte Grande, 47, 81-104. doi: http://dx.doi.org/10.4067/S0718-34022010000300005 
Mendez, R. (2010). La dimensión urbana del desarrollo territorial: significado actual de las ciudades de tamaño intermedio y las periferias metropolitanas. In C. Cornejo, J. Morán, \& J. Prada (Eds.), Ciudad, territorio y paisaje: una mirada multidisciplinar (pp. 137-154). Madrid.

Mendez, R., Abad, L. D., \& Echaves, C. (2015). Atlas de la crisis. Impactos socioeconómicos y territorios vulnerables en España. Valencia: Tirant lo Blanch.

Nel.lo, O. (1998). Los confines de la ciudad sin confines: estructura urbana y límites administrativos en la ciudad difusa. In F. J. Monclús (Ed.), La ciudad dispersa (pp. 35-57). Barcelona: Centro de Cultura Contemporània de Barcelona.

Nel.lo, O. (2004). ¿Cambio de siglo, cambio de ciclo?. Las grandes ciudades españolas en el umbral del siglo XXI. Ciudad y Territorio. Estudios Territoriales, 141-142, 523-542.

Nel.lo, O. (2007). "La tercera fase de metropolitanización en España. In O. Rullán et al. (Eds.), Los procesos urbanos postfordistas (pp. 33-46). Mallorca: Asociación de Geógrafos Españoles.

Nel.lo, O. (2017). El proceso de urbanización: motor y expresión de las transformaciones sociales y territoriales. In J. Romero (Coord.), Geografía Humana de España (pp. 289-366). Valencia: Universidad de Valencia.

Ponce, G. (2007). La ciudad fragmentada. Nuevas formas de hábitat. Alicante: Universidad de Alicante.

Pons, J. J. (2012). Metropolitanización: procesos y estructuras demográfico-territoriales. In La población en clave territorial. Procesos, estructuras y perspectivas de análisis (pp. 21-26). Santander: Asociación de Geógrafos Españoles y Universidad de Cantabria.

Portell, S. (2011, January 10). El juez de Castro investiga irregularidades urbanísticas en 630 casas y dos colegios. El Correo. Edición Vizcaya. Retrieved from http://www.elcorreo.com/vizcaya/v/20110110/vizcaya/juez-castro-investigairregularidades-20110110.html

Pujadas, I. (2009). Movilidad residencial y expansión urbana en la Región Metropolitana de Barcelona, 1982-2005. Scripta Nova, 290. Retrieved from http://www.ub.edu/geocrit/sn/sn290.htm

Roca, J., Moix, M., \& Arellano, B. (2012). El sistema urbano en España. Scripta Nova, 396. Retrieved from http://www.ub.edu/geocrit/sn/sn-396.htm

Rodríguez, F. (Ed.). (2009). Áreas metropolitanas de España: la nueva forma de la ciudad. Oviedo: Ediciones de la Universidad de Oviedo.

Ruiz, E. (2011, February 2). Castro pide a Vizcaya que rectifique y no le retire sus servicios sanitarios.

El Diario Montañés.

Retrieved 
from http://www.eldiariomontanes.es/v/20110202/region/region-oriental/castro-pide-vizcayarectifique-20110202.html

San Miguel, A. (2011, April 17). El padrón no engorda pero la economía sí. El Diario Montañés. Retrieved from hitp://www.eldiariomontanes.es/v/20110417/cantabria/padron-engorda-peroeconomia-20110417.html

Soja, E. (1997). Six Discourses on the Postmetropolis. In S. Westwood \& J. Williams (Eds.), Imagining Cities: Scripts, Signs, Memory (pp. 19-30). London: Routledge.

Soja, E. (2000). Postmetropolis. Oxford: Blackwell.

Soja, E. (2008). Postmetrópolis. Estudios críticos sobre las ciudades y las regiones. Madrid: Traficantes de sueños.

Torres, R. (2016). Expansión y reestructuración del parque residencial del País Vasco (1991-2011). Consolidación de patrones propios de la dispersión urbana. Boletín de la Asociación de Geógrafos Españoles, 72, 37-65.

Tribunal de Cuentas (2009). Informe de fiscalización del Ayuntamiento de Castro Urdiales, ejercicios 2004 y 2005 (Informe n. ${ }^{\circ}$ 826). Madrid. Retrieved from hitps://www.boe.es/diario_boe/txt.php?id=BOE-A-2010-214

Uriona, A. (2010, April 28). Transportes se plantea unir por tren Bilbao y Castro Urdiales. El País. Retrieved from https://elpais.com/diario/2010/04/28/paisvasco/1272483608_850215.html

Vahí, A., Rodríguez, V., \& Hurtado, C. (2015). Centralidad funcional y reconfiguración metropolitana. Boletín de la Asociación de Geógrafos Españoles, 68, 7-29. doi: http://dx.doi.org/10.21138/bage. 1851

Verano, A. (2010, September 13). (Nota de prensa). El Diario Montañés. Retrieved from http://www.eldiariomontanes.es/20100913/local/castro-oriental/nace-nuevo-partido-politico201009131932.html

Verano, A. (2011, February 2). El juez Acayro cierra la instrucción del caso Dirsur. El Diario Montañés. Retrieved from http://www.eldiariomontanes.es/20110202/local/castrooriental/imputan-prevaricacion-alcalde-castro-201102021610.html

Verano, A. (2012, January 18). Castro ha perdido 1,3 millones de euros en el desarrollo urbanístico de Santa Catalina. El Diario Montañés. Retrieved from http://www.eldiariomontanes.es/v/20120118/region/region-oriental/castro-perdidomillones-euros-20120118.html 
Verano, A. (2016, May 26). ¿Cuánta gente vive en Castro? El diario montañés. Retrieved from hitp://www.eldiariomontanes.es/castro-oriental/201605/27/cuanta-gente-vive-castro20160527125433.html

Verano, E. (2017, April 6). Vecinos de Castro reclaman una línea de autobús hasta Muskiz. El Diario Montañés. Retrieved from http://www.eldiariomontanes.es/castrooriental/201704/06/vecinos-castro-reclaman-linea-20170406000153-v.html

Vinuesa, J., \& Vidal, M². J. (1991). Los procesos de urbanización. Madrid: Síntesis.

Wiel, M. (1999). La Transition Urbaine. Le passage de la ville pédestre à la ville motorisée. Spirmont: Mardaga éditions.

n.a. (2014, April 25). TSJC admite querella de constructora contra el juez de Castro. Aquí Confidencial. Retrieved

from http://www.aquiconfidencial.es/es/notices/2014/03/tsjc_admite_querella_de_constructora 